\title{
ESTUDO DAS VAZÕES E ESTIMATIVAS DE INUNDAÇÕES NO BAIXO- AÇU-RN
}

\author{
STUDY OF FLOW AND FLOOD ESTIMATES IN BAIXO-AÇU-RN
}

\author{
Marysol Dantas de Medeiros'; Maria Elisa Zanella1 \\ ${ }^{1}$ Universidade Federal do Ceará (UFC), Fortaleza, CE, Brasil
}

Correspondência para: Maria Elisa Zanella (elisazv@terra.com.br)

doi: 10.12957/geouerj.2019.40946

Recebido em: 15 ago. 2018 | Aceito em: 19 out. 2018

\section{RESUMO}

O Nordeste brasileiro é associado a episódios de secas, entretanto é muito comum esta região ser acometida por eventos hidrometeóricos extremos com vários dias consecutivos de chuvas que resultam em inundações, não se restringindo apenas ao litoral, podendo ser até mesmo corriqueiros na região semiárida, dependendo das condições meteorológicas em determinado período. No estado do Rio Grande do Norte a principal causa para o acometimento de tais episódios de inundações foi derivado de fenômenos hidrometeóricos extremos, sobretudo a montante do Rio Piranhas-Açu. O objetivo deste trabalho foi realizar a modelagem hidrológica para diferentes períodos de retorno (5, 10, 50 e 100 anos) para se estimar as cotas de inundação na região do Baixo-Açu a partir do estudo das vazões do rio Piranhas-Açu. A modelagem foi elaborada a partir do levantamento de dados secundários junto ao Departamento Nacional de Obras Contra as Secas (DNOCS, 2012) e simulação hidrológica, utilizando o software HEC-versão 3.5. A modelagem mostrou que, até mesmo as cheias resultantes de vazões para períodos de retorno de baixo tempo de recorrência (5 e 10 anos), inundam grandes parcelas de áreas..

Palavras-chave: Inundações. Baixo-Açu. Período de Retorno. Modelagem Hidrológica. Vazões.

\section{ABSTRACT}

The Brazilian Northeast is associated with episodes of droughts, however it is very common that this region is affected by extreme hydrometeorological events with several consecutive days of rains that result in floods, not restricted only to the coast, and may even be commonplace also in the semi-arid region, depending on the meteorological conditions in a given period. In the state of Rio Grande do Norte, the main cause for the occurrence of such episodes of flooding was derived from extreme hydrometeorological phenomena, mainly upstream of the Piranhas-Açu River. The objective of this paper was to perform hydrological modeling for different return periods (5, 10, 50 and 100 years) to estimate the flood quotas in the Baixo-Açu region from the study of the Piranhas-Açu river flows. The modeling was elaborated from the secondary data collection with the Departamento Nacional de Obras Contra as Secas (DNOCS, 2012) and hydrological simulation using HEC-version 3.5 software. The modeling showed that, even floods resulting from flow rates for low recurrence times (5 and 10 years), flood large areas.

Keywords: Floods. Baixo-Açu. Return Period. Hydrological Modeling. Flows.

\section{INTRODUÇÃO}

O semiárido nordestino é conhecido por apresentar, frequentemente, episódios de estiagens e secas, chegando a formar um estereótipo sobre a região associada a essas características climáticas; porém, é muito comum no Nordeste brasileiro a ocorrência de inundações, enchentes e enxurradas causadas por eventos hidrometeóricos extremos com vários dias consecutivos de precipitações pluviométricas. 
Como apontado por Tucci (2011), a média das precipitações no semiárido nordestino, em torno dos 600 milímetros/ano, não são tão pequenas assim se comparados às precipitações de diversas cidades da Europa, porém, a variabilidade interanual alta faz com que as chuvas no semiárido nordestino sejam irregulares e concentradas.

Essa variação anual da precipitação é de difícil previsão além do que, a inconstância dos períodos de chuvas é determinante no comportamento das vazões dos rios ao longo do ano, uma vez que em anos com menos chuvas, a maioria dos rios diminuem o volume de suas vazões ao ponto de secarem completamente. Já quando as precipitações pluviométricas são mais elevadas, estes mesmos rios apresentam vazões extremas ao ponto de inundar extensas áreas. Contudo, vale lembrar que se as chuvas registradas mantiveram-se dentro da média esperada para o ano, as vazões dos rios só serão mais elevadas naqueles meses de maiores totais pluviométricos.

A cabeceira do Rio Piranhas-Açu encontra-se no limite dos estados da Paraíba, Ceará e Pernambuco. A bacia hidrográfica do rio Piranhas-Açu possui $1.500 \mathrm{~km}$ de perímetro e uma área equivalente a $44.000 \mathrm{~km}^{2}$, sendo a maior parte pertencente ao território da Paraíba (59\% da área da bacia) e a menor ao estado do Rio Grande do Norte (41\% do total da área da bacia). 0 rio principal tem nascente no município de Bonito de Santa Fé, na Serra de Piancó, no Estado da Paraíba, no qual recebe o nome de rio Piranhas. Apenas $147 \mathrm{~km}$ após sua nascente, ao se confluir com o rio Piancó passa a denominar-se rio Piranhas-Açu. Da nascente até a sua desembocadura no Oceano Atlântico o rio percorre cerca de $400 \mathrm{~km}$ de distância.

Em condições naturais se trata de um rio intermitente que tem sua perenidade assegurada por grandes reservatórios, o Coremas/Mãe d’Água, na Paraíba, com capacidade de 1,36 bilhões de m³ , e a barragem Eng. Armando Ribeiro Gonçalves, no Rio Grande do Norte, com capacidade de armazenamento de 2,4 bilhões de $\mathrm{m}^{3}$.

A área de estudo para este trabalho limita-se aos municípios que compõem o Baixo-Açu, ou seja, aqueles localizados após o vertedouro da Barragem Armando Ribeiro Gonçalves que são: Ipanguaçu, 
Açú, Afonso Bezerra, Alto do Rodrigues, Ipanguaçu, Itajá, Pendências, Carnaubais, Macau e Porto do Mangue (Figura 1).

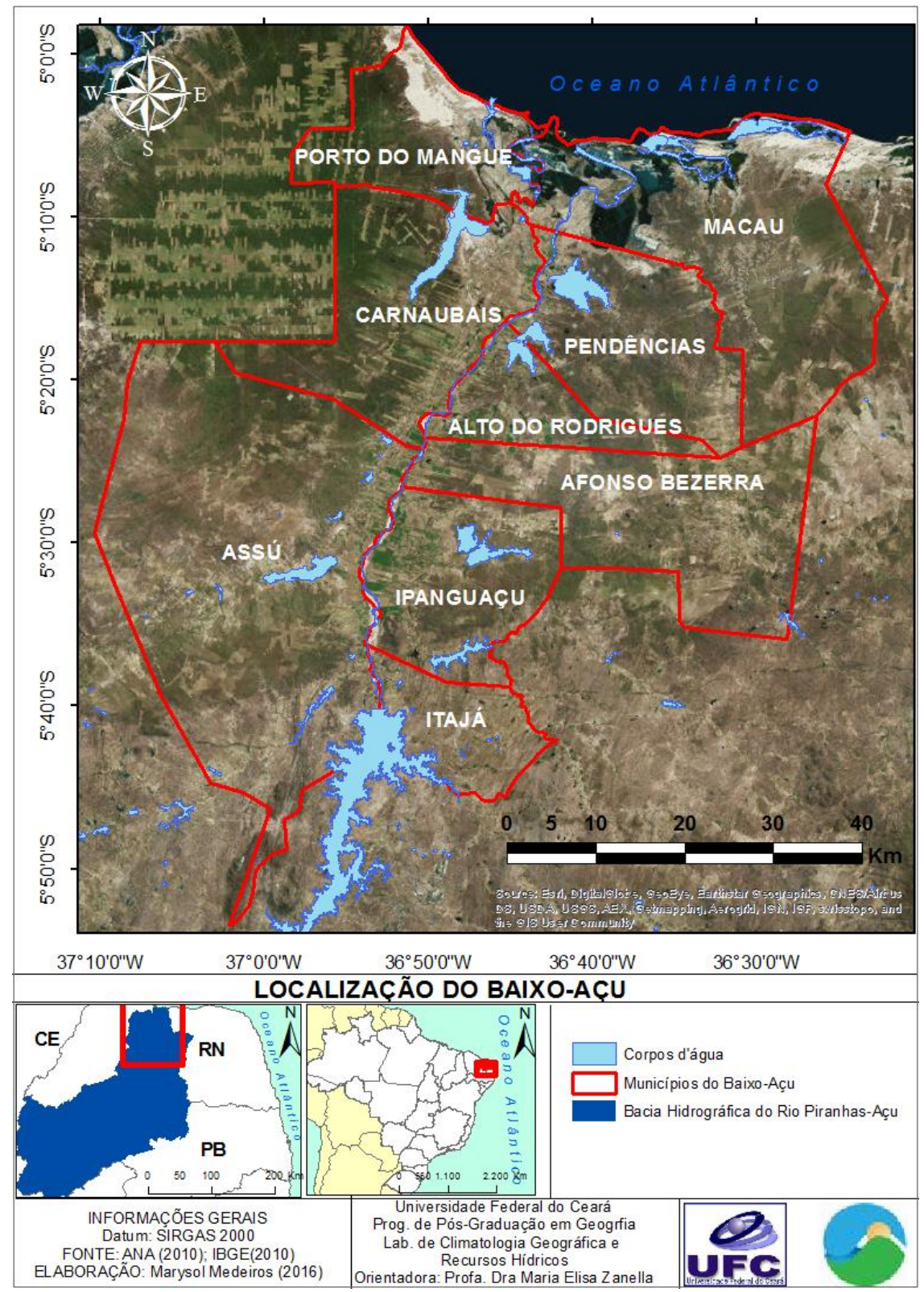

Figura 1: Localização da área de estudo Fonte: Elaborado pelas autoras a partir dados do IBGE (2010).

A maioria dos rios que compõem a bacia hidrográfica o rio Piranhas-Açu são intermites e, entre os meses de julho a dezembro, muitos deles não apresentam vazão devido à ausência de chuvas nessa época, diferentemente dos meses em que há atuação da Zona de Convergência Intertropical (ZCIT), entre fevereiro a maio, nos quais os rios apresentam as maiores vazões, conforme análise da Agência Nacional de águas (ANA, 2010). 
O objetivo deste trabalho é realizar a modelagem hidrológica para diferentes períodos de retorno (5, 10, 50 e 100 anos) para se estimar as cotas de inundação na região do Baixo-Açu a partir do estudo das vazões do rio Piranhas-Açu.

Para tanto, a modelagem foi elaborada a partir do levantamento de dados secundários junto ao Departamento Nacional de Obras Contra as Secas (DNOCS, 2012) e simulação hidrológica, utilizando o software HEC-HMS -Hydrologic Engineering Center / Hydrologic Modeling System Versão 3.5.

\section{EVENTOS HIDROCLIMÁTICOS EXTREMOS E DESASTRES}

Muitos desastres desenvolvem-se em consequência dos fenômenos climáticos extremos, que são situações meteorológicas anormais, caracterizadas pela ocorrência de valores meteorológicos ou climáticos acima ou abaixo do esperado. O Intergovernmental Panel on Climate Change (IPCC, 2012) acrescenta que alguns desastres naturais como secas e inundações podem ocorrer em decorrência de eventos climáticos não extremos, mas que o resultado da acumulação torna-se extrema, ou seja, as secas são deflagradas pela quantidade elevada de dias sem chuvas e as inundações podem ter sua gênese a partir do acúmulo de precipitações pluviométricas por vários dias, mesmo que essa precipitação não seja elevada.

Embora em muitos casos seja inevitável o desenvolvimento de um perigo natural, é possível a diminuição dos seus efeitos danosos. Para tanto, é preciso que haja um conhecimento prévio do perigo através da investigação da sua ocorrência em outras épocas, com que frequência costuma acontecer e realizar monitoramentos para se antecipar e evitar o risco de desastres.

As inundações estão diretamente relacionadas com as variações climatológicas, sobretudo, a episódios de precipitações pluviométricas que são frequentemente deflagrados por chuvas fortes e rápidas ou chuvas de longa duração. Segundo Kobiyama et. al. (2006), a inundação trata-se do aumento do nível da água dos rios além da sua vazão normal, ocorrendo o seu transbordamento sobre as áreas próximas a ele. 
Para prevenção de desastres naturais faz-se necessário o conhecimento prévio do perigo. Assim, no caso das inundações é importante analisar os fatores que podem desencadear e intensificar os efeitos adversos desse evento, mas também, é primordial conhecer a sazonalidade, ou o ciclo em que este ocorre, para então, conseguir elaborar medidas preventivas. Uma das formas de se analisar a ciclicidade das inundações e precipitações, ou de qualquer evento hidrológico extremo, é através de cálculos probabilísticos que levam em consideração a possibilidade de um evento extremo ocorrer ou ser superado em um determinado período de tempo. Uma dessas metodologias é o cálculo do período de retorno (PINTO et. al. 1976).

Período de retorno é o intervalo com que um evento hidrológico extremo pode ser igualado ou superado pelo menos uma vez. Seu cálculo é resultante do inverso da probabilidade de um dado valor ser superado (PINTO et. al. 1976).

Assim, através de dados de precipitações e/ ou vazões é possível calcular o período de retorno das inundações e predizer as possíveis áreas com maior probabilidade de ocorrer inundações e a frequência com a qual estas áreas são inundadas.

Dessa forma, mesmo em regiões semiáridas, que possuem baixos totais pluviométricos e consequentemente regimes fluviais intermitentes, é possível a realização de mapas de risco à inundações, pois se trata de um evento sazonal e que apresenta certa ciclicidade. Além do mais, metodologias com abordagens quantitativas permitem a elaboração de prognósticos futuros a partir de eventos ocorridos no passado.

\section{MODELAGEM HIDRODINÂMICA}

O estudo estatístico das vazões levou em conta as séries histórias simuladas pela empresa Acquatool Consultoria, a serviço do Departamento Nacional de Obras Contra as Secas (DNOCS), no ano de 2012, intitulado de "Estudos para proteção e controle de cheias na Bacia Hidrográfica do Rio Piranhas-Açu nos Estados da Paraíba e Rio Grande do Norte”. 
O trecho de interesse da simulação, compreendido entre a ponte da BR-304, próximo à cidade de Açu/RN e a foz do rio Piranhas-Açu, utilizou como dado de entrada as vazões de pico efluentes ao reservatório Armando Ribeiro Gonçalves somadas às vazões efluentes ao reservatório Mendubim, que são as duas contribuições mais significantes nesse trecho, na escala de avaliação do presente trabalho. A Tabela 1 apresenta as vazões máximas diárias obtidas para esses reservatórios, de 1964 a 2009 , destacados os anos de 2008 e 1974 quando foram observadas as maiores vazões em Armando Ribeiro e Mendubim, respectivamente.

\begin{tabular}{lcc}
\hline $\mathbf{A N O}$ & $\begin{array}{c}\text { Máx de Vazão Média Diária - Efluente ao } \\
\text { Reserv. Armando Ribeiro Gonçalves }\left(\mathbf{m}^{\mathbf{3}} / \mathbf{s}\right)\end{array}$ & $\begin{array}{c}\text { Máx de Vazão Média Diária - Efluente ao } \\
\left.\text { Reserv. Mendubim(m } \mathbf{m}^{\mathbf{3}} / \mathbf{s}\right)\end{array}$ \\
\hline $\mathbf{1 9 6 4}$ & $1.853,51$ & 44,66 \\
$\mathbf{1 9 6 5}$ & $1.628,49$ & 46,90 \\
$\mathbf{1 9 6 6}$ & 168,49 & 15,20 \\
$\mathbf{1 9 6 7}$ & $3.161,48$ & 40,31 \\
$\mathbf{1 9 6 8}$ & $1.844,24$ & 25,73 \\
$\mathbf{1 9 6 9}$ & 380,22 & 18,53 \\
$\mathbf{1 9 7 0}$ & 266,57 & 6,043 \\
$\mathbf{1 9 7 1}$ & $1.386,77$ & 52,19 \\
$\mathbf{1 9 7 2}$ & 181,13 & 16,91 \\
$\mathbf{1 9 7 3}$ & $1.238,09$ & 35,41 \\
$\mathbf{1 9 7 4}$ & $4.570,93$ & $\mathbf{1 2 6 , 6 6}$ \\
$\mathbf{1 9 7 5}$ & $1.516,14$ & 63,54 \\
$\mathbf{1 9 7 6}$ & 460,38 & 14,75 \\
$\mathbf{1 9 7 7}$ & $3.478,19$ & 56,92 \\
$\mathbf{1 9 7 8}$ & 645,52 & 24,16 \\
$\mathbf{1 9 7 9}$ & 197,94 & 8,29 \\
$\mathbf{1 9 8 0}$ & $1.503,65$ & 7,90 \\
$\mathbf{1 9 8 1}$ & $2.144,21$ & 72,88 \\
$\mathbf{1 9 8 2}$ & 409,07 & 21,73 \\
$\mathbf{1 9 8 3}$ & 94,77 & 5,17 \\
$\mathbf{1 9 8 4}$ & 557,54 & 25,05 \\
\hline & & \\
$\mathbf{1 9}$ & &
\end{tabular}




\begin{tabular}{|c|c|c|}
\hline 1985 & $4.317,43$ & 123,06 \\
\hline 1986 & $1.113,24$ & 41,63 \\
\hline 1987 & 364,48 & 13,70 \\
\hline 1988 & $1.816,33$ & 5,59 \\
\hline 1989 & $1.122,26$ & 19,82 \\
\hline 1990 & 68,60 & 0,55 \\
\hline 1991 & 347,25 & 17,51 \\
\hline 1992 & 218,63 & 7,03 \\
\hline 1993 & 20,79 & 0,08 \\
\hline 1994 & 123,21 & 6,31 \\
\hline 1995 & 776,08 & 29,41 \\
\hline 1996 & 928,44 & 21,47 \\
\hline 1997 & 109,73 & 1,85 \\
\hline 1998 & 17,21 & 0,29 \\
\hline 1999 & 208,10 & 0,43 \\
\hline 2000 & 296,21 & 3,54 \\
\hline 2001 & 96,06 & 0,04 \\
\hline 2002 & 256,41 & 21,91 \\
\hline 2003 & 76,07 & 0,10 \\
\hline 2004 & $2.631,23$ & 53,43 \\
\hline 2005 & 190,06 & 1,76 \\
\hline 2006 & 704,26 & 11,39 \\
\hline 2007 & 181,29 & 1,24 \\
\hline 2008 & $5.002,85$ & 28,05 \\
\hline 2009 & $2.490,06$ & 51,68 \\
\hline
\end{tabular}

Tabela 1. Séries de Vazões de Pico Fonte: Acquatool Consultoria, 2012

Segundo Pinto et. al. (1976), a frequência de uma vazão Q é, em geral, expressa em termos de período de retorno T, com o significado de que, na seção considerada, ocorrerão valores iguais ou superiores ao valor $\mathrm{Q}$ apenas uma vez a cada $\mathrm{T}$ anos. 
Dessa forma, uma cheia com período de retorno de 50 anos tem, por exemplo, a probabilidade de 1/50, ou $2 \%$ de ocorrência em qualquer ano. Portanto, a probabilidade de não excedência desse evento em qualquer ano é de 1-0,02 =0,98 ou 98\%.

Partindo-se dessa premissa, foram avaliadas as séries de vazões apresentadas previamente, adotandose diversas distribuições de frequência, as que permitem calcular as probabilidades de ocorrência das vazões, e consequentemente, os valores de vazões correspondentes aos períodos de retorno de 5, 20, 50 e 100 anos. Os resultados dessas distribuições são mostrados na Tabela 2.

\begin{tabular}{|c|c|c|c|c|c|c|c|}
\hline \multirow[b]{2}{*}{ Reservatório } & \multirow[b]{2}{*}{$\mathrm{T}$ (anos) } & \multicolumn{6}{|c|}{$\mathrm{Q}\left(\mathrm{m}^{3} / \mathrm{s}\right)$} \\
\hline & & $\begin{array}{c}\log _{-} \\
\text {Normal } 2\end{array}$ & $\begin{array}{c}\text { Log- } \\
\text { Normal } 3\end{array}$ & Gumbel & $\begin{array}{l}\text { Log- } \\
\text { Gumbel }\end{array}$ & $\begin{array}{l}\text { Pearson } \\
\text { III }\end{array}$ & $\begin{array}{c}\text { Log- } \\
\text { Pearson } \\
\text { III }\end{array}$ \\
\hline \multirow{4}{*}{$\begin{array}{l}\text { Armando Ribeiro } \\
\text { Gonçalves }\end{array}$} & 5 & $1.700,30$ & $1.987,33$ & $2.177,24$ & $1.644,99$ & $1.991,77$ & $1.727,25$ \\
\hline & 10 & $3.205,28$ & $2.801,75$ & $3.015,71$ & $4.104,77$ & $2.848,31$ & $2.998,51$ \\
\hline & 50 & $10.070,96$ & $4.778,58$ & $4.861,04$ & $30.711,16$ & $4.849,97$ & $7.506,75$ \\
\hline & 100 & $15.292,28$ & $5.705,72$ & $5.641,17$ & $71.909,70$ & $5.741,34$ & $10.240,47$ \\
\hline \multirow{4}{*}{ Mendubim } & 5 & 51,07 & 44,13 & 49,7 & 48,8 & 43,82 & 50,06 \\
\hline & 10 & 121,95 & 62,8 & 68,45 & 171,26 & 63,91 & 78,85 \\
\hline & 50 & 587,26 & 110,45 & 109,7 & $2.714,37$ & 113,16 & 135,72 \\
\hline & 100 & $1.042,06$ & 133,73 & 127,14 & $8.729,3$ & 135,79 & 153,73 \\
\hline
\end{tabular}

Tabela 2. Distribuições de probabilidade das séries históricas de vazões Fonte: Elaborada pelas autoras.

As referidas vazões foram obtidas por meio de software de cálculo estatístico, o qual permite ainda selecionar qual a melhor distribuição, através do teste de aderência do chi-quadrado $\left(\mathrm{X}^{2}\right)$. Este teste serve para avaliar quantitativamente a relação entre o resultado de um experimento e a distribuição esperada para esse fenômeno.

No caso avaliado, os resultados apontam que a distribuição de Pearson Tipo III, usualmente empregada na caracterização de eventos hidrológicos, é a que possui melhor ajuste à curva de distribuições e, portanto foi a selecionada. 
A Tabela 3 mostra o resultado final dos dados de vazão de pico para cada período de ocorrência, já considerando o somatório para os dois reservatórios, que serão os dados de entrada para a modelagem hidrodinâmica dos eventos de cheia do Rio Piranhas-Açu.

\begin{tabular}{cc}
\hline Período de retorno & Vazão de pico a ser adotada na modelagem \\
\hline 5 anos & $2.035,59 \mathrm{~m}^{3} / \mathrm{s}$ \\
10 anos & $2.912,22 \mathrm{~m}^{3} / \mathrm{s}$ \\
50 anos & $4.963,13 \mathrm{~m}^{3} / \mathrm{s}$ \\
100 anos & $5.877,13 \mathrm{~m}^{3} / \mathrm{s}$ \\
\hline
\end{tabular}

Tabela 3. Resultados das vazões de pico para os tempos de retorno Fonte: Elaborada pelas autoras.

Os modelos hidrodinâmicos unidimensionais se baseiam nas equações de conservação da massa e da quantidade de movimento do fluido em um volume de controle, cujo sistema de equações é conhecido como equações de Saint Venant (OLIVEIRA et. al. 2016).

De acordo com Porto (1999), as equações completas do escoamento requerem técnicas numéricas muito elaboradas, portanto são adotadas algumas hipóteses simplificadoras para sua dedução: 0 escoamento é unidimensional; o fluído é incompressível; variação gradual das seções transversais; a declividade da linha de energia pode ser calculada através das leis de Manning e Chézy; a aceleração vertical é desprezível e a variação da pressão na vertical é hidrostática.

O modelo Hydrologic Engineering Center - River Analysis System (HEC-RAS), desenvolvido pelo Corpo de Engenheiros do Exército dos Estados Unidos da América (USACE), é um dos modelos usualmente empregados nessas situações. Quando utilizado em concordância com a extensão HECGeoRAS, esse modelo é capaz de processar os dados de entrada e saída de forma georreferenciada associada a Sistemas de Informações Geográficas (SIG).

O modelo representado considerou o trecho do Baixo Piranhas-Açu, a jusante da Barragem Eng. Armando Ribeiro Gonçalves, que tem início na Ponte da BR-304 (Seção 09) em Açu-RN, e o final na foz do rio, na cidade de Macau-RN, percorrendo mais de $70 \mathrm{~km}$ de extensão (Figura 2). 
Selecionou-se nove seções para a realização dos perfis transversais do rio, em que foram coletados os dados altimétricos por meio de uma estação total. Os perfis transversais representam a geomorfologia da calha do rio nos trechos selecionados e serviram de parâmetro para a realização da modelagem hidrodinâmica.

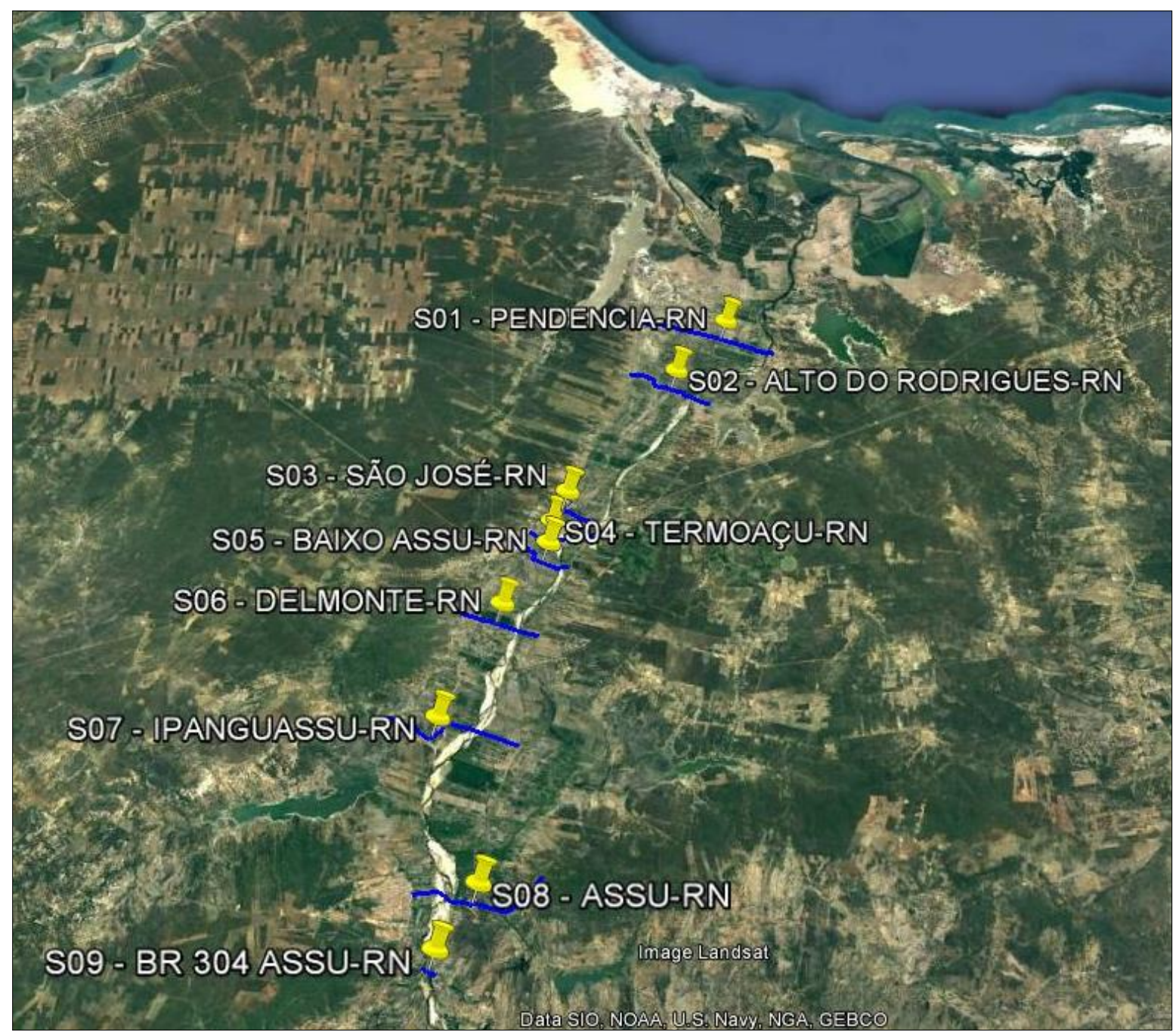

Figura 2: Seções selecionadas para realização dos perfis transversais Fonte: Elaborado pelas autoras a partir de dados do

DNOCS (2012).

Sabe-se que as regiões estuarinas do Rio Piranhas-Açu sofrem importantes influências advindas da variação do nível da maré na sua foz. Tal fenômeno foi computado como condição de contorno à jusante da modelagem, onde foram utilizados os dados do nível dinâmico da água, medido pelo Marégrafo instalado nessa área. Como condição de contorno de montante, foram aplicadas as vazões calculadas, em regime constante, na seção inicial do rio. 
Portanto, apesar das vazões principais serem aplicadas em regime permanente (sem variação com o tempo), a simulação hidrodinâmica assumiu um regime de escoamento transiente, pois houve variações de vazões com o tempo, devido às variações das marés.

O pré-processamento dos dados consistiu, primeiramente, na criação de um Modelo Digital de Elevação (MDE), a partir de dados extraídos da missão SRTM - Shuttle Radar Topographic Mission, executado pela NASA - National Aeronautics and Space Administration. O MDT disponibilizado tem formato em grids e resolução planimétrica de 30 metros. Segundo estudos de Araújo et.al. (2018), os mesmos chegaram à conclusão que os dados do SRTM para a área do Vale do Açu possuem uma acurácia vertical de $3,10 \mathrm{~m}$, ou seja, bem mais preciso do que a especificada pelo SRTM para América do Sul, que é 6,20 metros.

A imagem em formato raster do SRTM foi manipulada no software de Sistema de Informações Geográfica (SIG) ArcGis 10.5. O MDE obtido contém valores de altimetria, com resolução espacial compatível com a escala de avaliação do trabalho, o que permite a representação digital satisfatória do relevo da área em estudo.

Em seguida, fez-se necessária a vetorização dos elementos fundamentais para a modelagem, tais como a linha central do leito do rio, as margens direita e esquerda e as seções transversais. Todos esses elementos são definidos como "layers" padrão da extensão HEC-GeoRAS, onde foram armazenados os metadados, além das coordenadas geográficas.

Após a criação de todo o banco de dados no SIG, procede-se à exportação do mesmo para um arquivo cujo foi feita a importação dos dados geométricos pelo HEC-RAS, resultando no traçado principal do rio e seções transversais, com as distâncias entre elas já calculadas automaticamente pelo software, conforme mostrado na Figura 3. Nesse caso observa-se a criação de um total de 9 seções (levantadas pela topografia) ao longo do rio. 


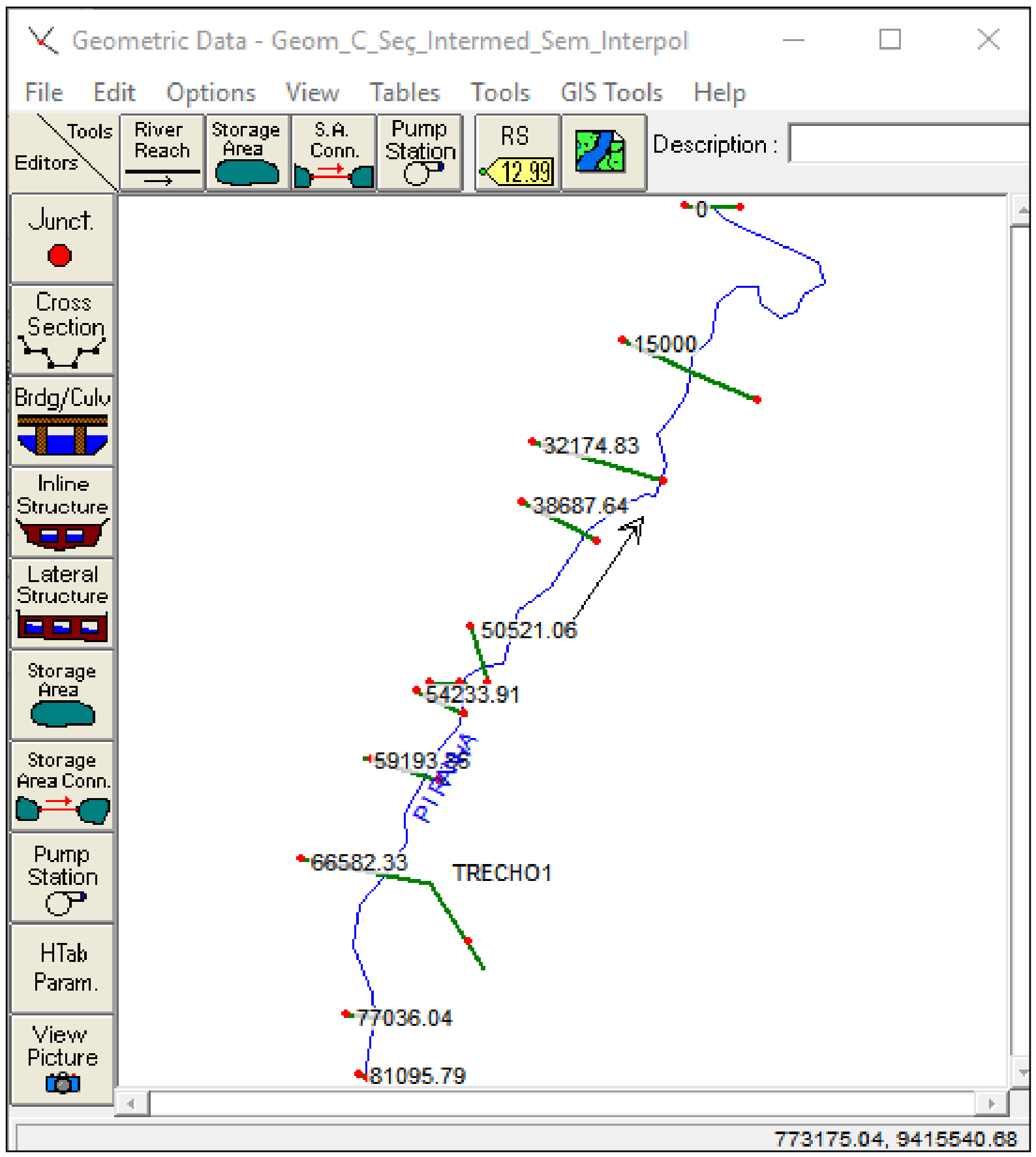

Figura 3. Leitura da geometria importada pelo HEC-RAS. Fonte: Elaborada pelas autoras.

Uma prática recomendada para esse tipo de simulação, devido à longa extensão do corpo hídrico, é a interpolação de seções. Essa função presente no software, apresentada na Figura 4, é feita de forma automática, de maneira a calcular uma seção média entre duas seções conhecidas, e assim diminuir as distâncias livres de escoamento. 


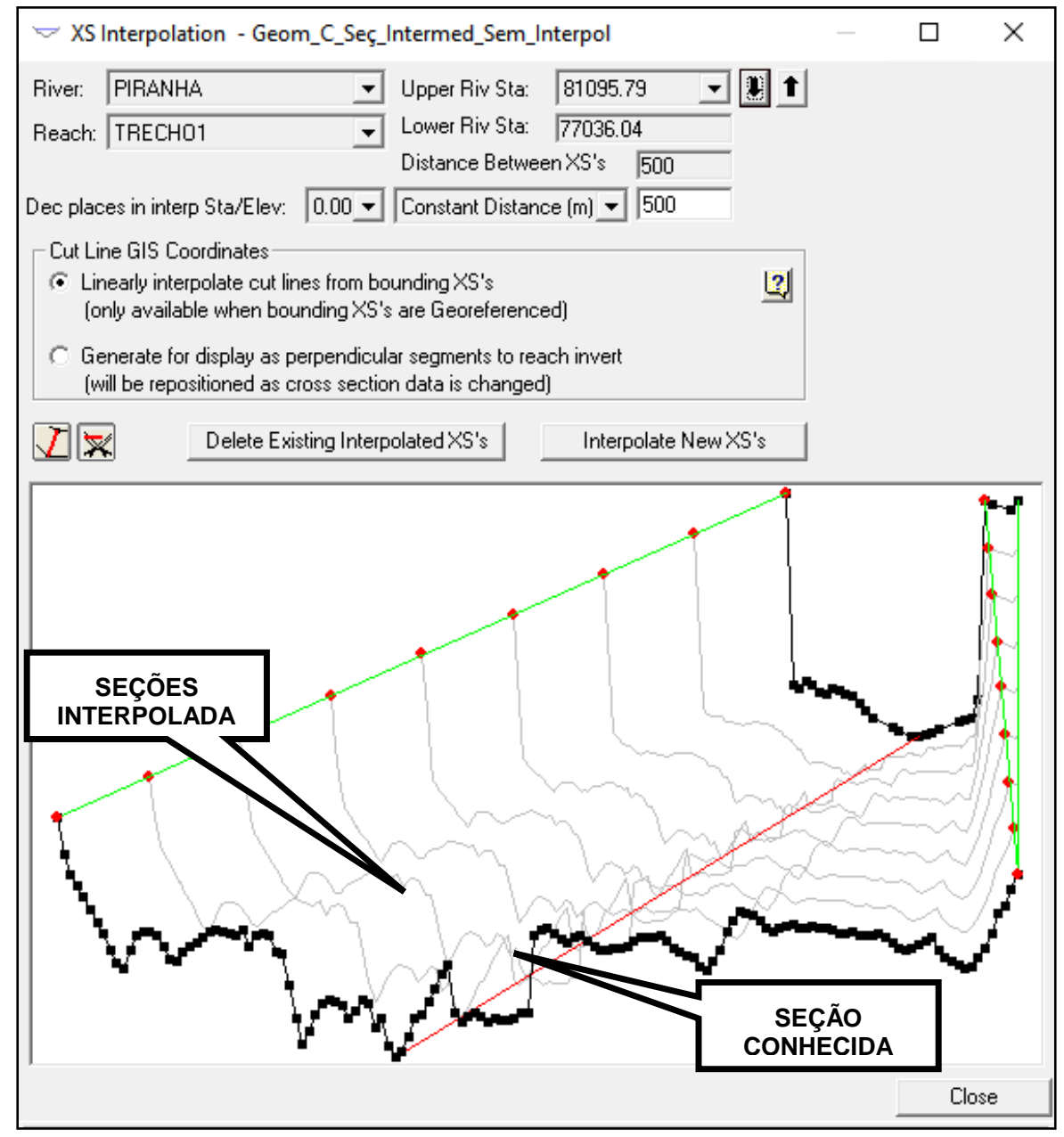

Figura 4. Ferramenta para interpolação de seções. Fonte: Elaborada pelas autoras.

Ainda no que diz respeito aos dados da geometria das seções, é necessária a entrada dos valores dos coeficientes de rugosidade de Manning (n) para cada seção, podendo assumir distintos valores na margem esquerda, na calha do rio leito e na margem direita. Esses valores influenciam diretamente no cálculo das vazões de escoamento, portanto deve-se avaliar a literatura para a determinação mais precisa possível desse parâmetro. No caso em estudo, foi utilizado como referência as recomendações presentes das obras de Chow (1959), sendo assim, para o Rio Piranhas-Açu, adotou-se o coeficiente de 0,035 , que pode ser entendido como um curso natural com calha principal parcialmente limpa, com presença de algumas pedras e arbustos, e uma planície de inundação com presença de grama (pasto). A prática tem mostrado que esse valor, no caso geral, se adequa bem à realidade dos corpos hídricos do Nordeste brasileiro, quando não há muita precisão sobre os mais diferentes tipos de revestimento e obstáculos que podem acometer os trechos dos rios.

Na sequência do processo, uma vez consolidados todos os parâmetros geométricos, foi requerida a entrada dos dados hidráulicos, de vazão e condições de contorno. Nesse caso em estudo, foram 
utilizados, basicamente, 2 tipos de dados de entrada nessa modelagem, para cada simulação: o dado 1 "flow hydrograph" diz respeito às vazões de montante, efluentes ao reservatório Armando Ribeiro Gonçalves, para cada período de retorno da simulação, e o dado 2 "stage hydrograph" contém a variação das cotas altimétricas em função do tempo, na foz do rio (marés).

A tabela com os níveis de variação das marés foi obtida a partir do mesmo estudo do DNOCS referido de 2012, onde foram levantados em campo os valores da cota do rio durante um período de 30 dias.

Por conta da insuficiência de dados batimétricos da calha dos rios não foi possível a criação de um MDE com precisão detalhado das inundações ao longo dos diferentes períodos de retorno. Assim, os resultados da modelagem serão expressos por meio de gráficos e tabelas mostrando o nível da água em cada uma das seções levantadas.

Todo este processo serviu para encontrar as cotas das inundações para os períodos de retorno de 5, 20, 50 e 100 anos e sua relação com as vazões máximas registradas na bacia hidrográfica.

\section{AS VAZÕES MÁXIMAS E PERÍODOS DE RETORNO DAS INUNDAÇõES NO BAIXO-AÇU}

Para entender as inundações que ocorrem no Baixo-Açu é preciso, antes de tudo, compreender a influência que a Barragem Eng. Armando Ribeiro Gonçalves exerce sobre o regime hídrico e hidráulico do rio Piranhas-Açu.

O reservatório recebe todos os afluentes do Rio Piranhas-Açu, antes do rio chegar ao seu baixo curso e, por este motivo, se torna o principal elemento amortecedor das cheias na região. Ainda, o PiranhasAçu naturalmente é um rio intermitente e o que garante a perenidade do mesmo é a barragem que libera volumes de água através do seu vertedouro.

Todavia, quando na cabeceira ou nos rios contribuintes à montante do rio Piranhas-Açu há elevadas precipitações pluviométricas (episódios extremos de chuva) a vazão dos afluentes aumenta, sobrecarregando a capacidade de armazenamento da Barragem, o que gera altas vazões de efluentes da barragem para o Baixo-Açu. 
As vazões dos rios da bacia Piranhas-Açu apresentam sazonalidades e amplitudes de valores bem discrepantes durante o ano, tendo forte dependência das condições climáticas de cada ano.

Como já descrito previamente, foram realizadas 4 simulações, envolvendo um período contínuo de 60 dias, tempo suficiente tanto para o aquecimento matemático do modelo hidráulico HEC-RAS, como para englobar um período crítico de vazões.

As Tabelas 4, 5, 6 e 7 apresentam, respectivamente, os resultados dos principais parâmetros dos modelados para as vazões com períodos de retorno de 5, 10, 50 e 100 anos, com destaque para a cota máxima atingida pela água durante a simulação, em cada seção.

\begin{tabular}{|c|c|c|c|c|c|c|c|}
\hline $\begin{array}{c}\text { Seção do } \\
\text { Levantamento }\end{array}$ & $\begin{array}{c}\text { Estaqueamento } \\
\text { do Rio (m) }\end{array}$ & $\begin{array}{l}\text { Q Total } \\
(\mathrm{m} 3 / \mathrm{s})\end{array}$ & $\begin{array}{l}\text { Elev. } \\
\text { Mín. } \\
(m)\end{array}$ & $\begin{array}{l}\text { N.A. }^{1} \\
\text { Máx } \\
\text { (m) }\end{array}$ & $\begin{array}{c}\text { Velocidade } \\
(\mathrm{m} / \mathrm{s})\end{array}$ & $\begin{array}{l}\text { Área } \\
(\mathrm{m} 2)\end{array}$ & Froude \\
\hline S09 & $81.095,79$ & $2.035,59$ & 17,13 & 21,36 & 1,11 & $1.839,12$ & 0,2 \\
\hline S08 & $77.036,04$ & $2.000,00$ & 15,87 & 19,61 & 1,34 & $1.496,03$ & 0,32 \\
\hline S07 & $66.582,33$ & $2.035,59$ & 10,88 & 14,32 & 0,48 & $4.224,73$ & 0,13 \\
\hline S06 & $59.193,86$ & $2.035,59$ & 7,85 & 13,37 & 0,62 & $3.264,82$ & 0,2 \\
\hline S05 & $54.233,91$ & $2.035,59$ & 5,7 & 11,12 & 0,64 & $3.192,79$ & 0,18 \\
\hline S04 & $52.291,02$ & $2.035,59$ & 5,11 & 10,62 & 0,69 & $2.938,93$ & 0,17 \\
\hline S03 & $50.521,06$ & $2.035,59$ & 4,15 & 9,59 & 0,92 & $2.210,92$ & 0,2 \\
\hline S02 & $38.687,64$ & $2.000,00$ & 2,11 & 6,52 & 0,45 & $4.486,34$ & 0,13 \\
\hline S01 & $32.174,83$ & $2.105,33$ & 0,32 & 3,86 & 0,88 & $2.402,67$ & 0,35 \\
\hline Marégrafo & 0 & $\begin{array}{c}- \\
1.770,54\end{array}$ & $-1,5$ & 1,44 & $-0,15$ & $11.757,97$ & 0,03 \\
\hline
\end{tabular}

Tabela 4. Resultados da simulação para $\mathrm{TR}=5$ anos Fonte: Elaborada pelas autoras

\begin{tabular}{ccccccccc}
\hline $\begin{array}{c}\text { Seção do } \\
\text { Levantamento }\end{array}$ & $\begin{array}{c}\text { Estaqueamento } \\
\text { do Rio }(\mathrm{m})\end{array}$ & Q Total & $\begin{array}{c}\text { Elev. } \\
\text { Mín. }\end{array}$ & $\begin{array}{c}\text { N.A. } \\
\text { Máx }\end{array}$ & $\begin{array}{c}\text { Velocidade } \\
(\mathrm{m} 3 / \mathrm{s})\end{array}$ & $\begin{array}{c}\text { Área } \\
(\mathbf{m})\end{array}$ & $\begin{array}{c}(\mathrm{m} / \mathrm{s}) \\
(\mathrm{m} 2)\end{array}$ & Froude \\
\hline $\mathbf{S 0 9}$ & $81.095,79$ & $2.912,22$ & 17,13 & $\mathbf{2 2 , 0 6}$ & 1,3 & $2.240,43$ & 0,21 \\
$\mathbf{S 0 8}$ & $77.036,04$ & $2.910,61$ & 15,87 & $\mathbf{1 9 , 9 4}$ & 1,61 & $1.806,21$ & 0,39 \\
\hline
\end{tabular}

\footnotetext{
${ }^{1}$ Nível de água
} 


\begin{tabular}{|c|c|c|c|c|c|c|c|}
\hline S07 & $66.582,33$ & $2.912,22$ & 10,88 & 14,68 & 0,52 & $5.558,35$ & 0,14 \\
\hline S06 & $59.193,86$ & $2.911,93$ & 7,85 & 13,65 & 0,69 & $4.205,86$ & 0,2 \\
\hline S05 & $54.233,91$ & $2.912,22$ & 5,7 & 11,62 & 0,64 & $4.562,71$ & 0,16 \\
\hline S04 & $52.291,02$ & $2.912,22$ & 5,11 & 11,22 & 0,71 & $4.073,63$ & 0,16 \\
\hline S03 & $50.521,06$ & $2.912,22$ & 4,15 & 10,12 & 1,04 & $2.787,15$ & 0,22 \\
\hline S02 & $38.687,64$ & $2.891,94$ & 2,11 & 6,7 & 0,56 & $5.207,52$ & 0,16 \\
\hline \multirow[t]{2}{*}{ S01 } & $32.174,83$ & $2.999,32$ & 0,32 & 4,08 & 0,89 & $3.366,93$ & 0,34 \\
\hline & & & & & & $11.757,9$ & \\
\hline Marégrafo & 0 & 933,85 & $-1,5$ & 1,44 & 0,08 & 7 & 0,01 \\
\hline
\end{tabular}

Tabela 5. Resultados da simulação para $\mathrm{TR}=10$ anos Fonte: Elaborada pelas autoras

\begin{tabular}{|c|c|c|c|c|c|c|c|}
\hline $\begin{array}{c}\text { Seção do } \\
\text { Levantamento }\end{array}$ & $\begin{array}{c}\text { Estaqueamento } \\
\text { do Rio (m) }\end{array}$ & $\begin{array}{l}\text { Q Total } \\
(\mathrm{m} 3 / \mathrm{s})\end{array}$ & $\begin{array}{l}\text { Elev. } \\
\text { Mín. } \\
(\mathrm{m})\end{array}$ & $\begin{array}{l}\text { N.A. } \\
\text { Máx } \\
\text { (m) }\end{array}$ & $\begin{array}{l}\text { Velocidade } \\
(\mathrm{m} / \mathrm{s})\end{array}$ & $\begin{array}{l}\text { Área } \\
\text { (m2) }\end{array}$ & Froude \\
\hline S09 & $81.095,79$ & $4.963,13$ & 17,13 & 23,39 & 1,65 & $3.008,42$ & 0,23 \\
\hline S08 & $77.036,04$ & $4.962,57$ & 15,87 & 20,67 & 1,79 & $2.778,21$ & 0,45 \\
\hline SOF & $66.582,33$ & $4.963,13$ & 10,88 & 15,23 & 0,61 & $8.072,14$ & 0,16 \\
\hline S06 & $59.193,86$ & $4.963,13$ & 7,85 & 14,13 & 0,83 & $5.950,88$ & 0,21 \\
\hline S05 & $54.233,91$ & $4.963,13$ & 5,7 & 12,54 & 0,68 & $7.324,59$ & 0,14 \\
\hline S04 & $52.291,02$ & $4.963,13$ & 5,11 & 12,26 & 0,77 & $6.471,20$ & 0,15 \\
\hline S03 & $50.521,06$ & $4.963,13$ & 4,15 & 11,06 & 1,1 & $4.493,94$ & 0,25 \\
\hline S02 & $38.687,64$ & $4.951,95$ & 2,11 & 7,09 & 0,72 & $6.888,88$ & 0,19 \\
\hline \multirow[t]{2}{*}{ S01 } & $32.174,83$ & $5.105,22$ & 0,32 & 4,44 & 0,96 & $5.302,04$ & 0,32 \\
\hline & & & & & & $11.757,9$ & \\
\hline Marégrafo & 0 & $5.761,49$ & $-1,5$ & 1,44 & 0,49 & 7 & 0,09 \\
\hline
\end{tabular}

Tabela 6. Resultados da simulação para $\mathrm{TR}=50$ anos. Fonte: Elaborada pelas autoras.

\begin{tabular}{ccccccccc}
\hline $\begin{array}{c}\text { Seção do } \\
\text { Levantamento }\end{array}$ & $\begin{array}{c}\text { Estaqueamento } \\
\text { do Rio }(\mathrm{m})\end{array}$ & Q Total & $\begin{array}{c}\text { Elev. } \\
\text { Mín. }\end{array}$ & $\begin{array}{c}\text { N.A. } \\
\text { Máx }\end{array}$ & Velocidade & Área & Froude \\
\hline S09 & $81.095,79$ & $5.877,13$ & 17,13 & $\mathbf{2 4 , 9 7}$ & 1,49 & $3.938,08$ & 0,18 \\
S08 & $77.036,04$ & $5.877,13$ & 15,87 & $\mathbf{2 1 , 5 9}$ & 1,18 & $4.993,96$ & 0,28 \\
\hline \hline
\end{tabular}




\begin{tabular}{r|ccccccc}
$\mathbf{S 0 7}$ & $66.582,33$ & $5.877,13$ & 10,88 & $\mathbf{1 5 , 3 9}$ & 0,65 & $8.977,58$ & 0,17 \\
$\mathbf{S 0 6}$ & $59.193,86$ & $5.877,13$ & 7,85 & $\mathbf{1 4 , 9 7}$ & 1,09 & $5.377,57$ & 0,29 \\
$\mathbf{S 0 5}$ & $54.233,91$ & $5.877,13$ & 5,7 & $\mathbf{1 2 , 9 7}$ & 0,68 & $8.614,85$ & 0,13 \\
$\mathbf{S 0 4}$ & $52.291,02$ & $5.877,12$ & 5,11 & $\mathbf{1 2 , 5 7}$ & 0,81 & $7.368,47$ & 0,15 \\
$\mathbf{S 0 3}$ & $50.521,06$ & $5.877,13$ & 4,15 & $\mathbf{1 1 , 2 9}$ & 1,17 & $5.021,07$ & 0,25 \\
$\mathbf{S 0 2}$ & $38.687,64$ & $5.874,08$ & 2,11 & $\mathbf{7 , 6}$ & 0,63 & $9.267,91$ & 0,14 \\
$\mathbf{S 0 1}$ & $32.174,83$ & $6.108,73$ & 0,32 & $\mathbf{5 , 0 4}$ & 0,65 & $9.350,91$ & 0,19 \\
\hline $\mathbf{S a r e ́ g r a f o ~}$ & & & & & & $11.757,9$ & \\
\hline
\end{tabular}

Tabela 7. Resultados da simulação para $\mathrm{TR}=100$ anos Fonte: Elaborada pelas autoras.

Tais resultados obtidos podem ser comparados aos valores registrados de cheias históricas observados na região, de acordo com os relatos de moradores locais como forma de confirmar a eficácia do modelo. A Figura 5 mostra o nível já atingido pela água na rua José Leão, no município de Açu-RN. A moradora da casa relatou que no ano de 1974, a água chegou até a altura da janela das residências.

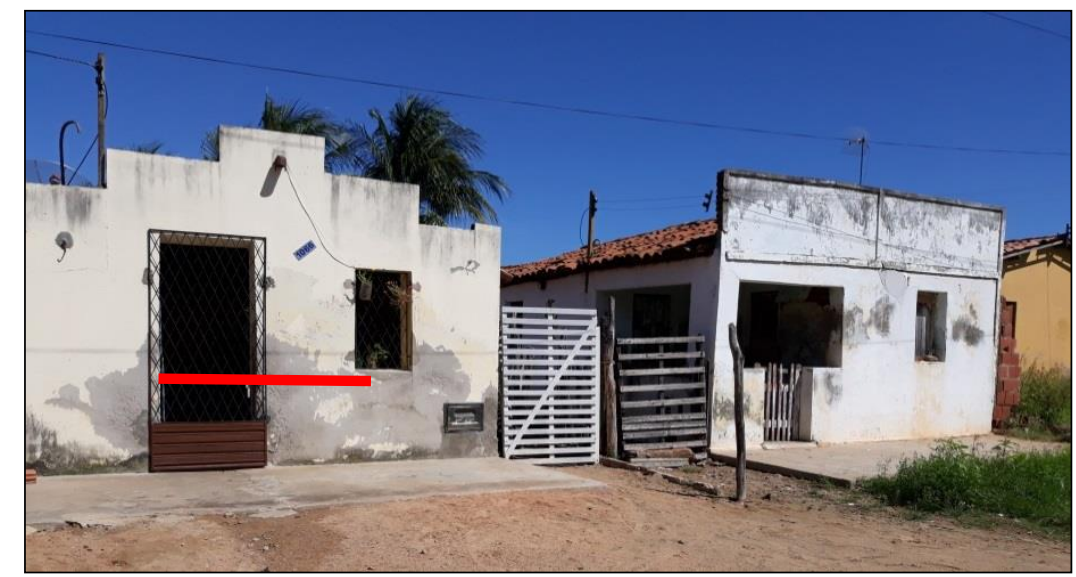

Figura 5: Altura atingida pela água na inundação de 1974, sinalizada pela linha vermelha. Fonte: Arquivo pessoal, 27 de maio de 2018

Sabendo que os maiores valores históricos de vazão do qual se tem registro no Rio Piranhas-Açu está entre os valores obtidos para o período de retorno de 50 e 100 anos, realizou-se a comparação entre a média desses valores simulados no software Hec-Ras e as cotas registradas em campo, conforme explicitado na tabela 8. 


\begin{tabular}{ccccc}
\hline $\begin{array}{c}\text { Seção do } \\
\begin{array}{c}\text { Levantamento } \\
\text { Topográfico }\end{array}\end{array}$ & $\begin{array}{c}\text { Cota de Cheia } \\
\text { Máxima } \\
\text { Histórica }(\mathrm{m})\end{array}$ & $\begin{array}{c}\text { Média entre as cotas } \\
\text { para TR 50 e 100 } \\
\text { anos }(\mathrm{m})\end{array}$ & $\begin{array}{c}\text { Diferença entre cotas } \\
(\mathrm{m})\end{array}$ & $\begin{array}{c}\text { Erro Médio } \\
\text { Absoluto } \\
(\%)\end{array}$ \\
\hline \hline S09 & 23.75 & 24.18 & -0.43 & $1.8 \%$ \\
S08 & 22.48 & 21.13 & 1.35 & $6.0 \%$ \\
S07 & 18.88 & 15.31 & 3.57 & $18.9 \%$ \\
S06 & 12.49 & 14.05 & -1.56 & $12.5 \%$ \\
S05 & 15.08 & 12.76 & 2.33 & $15.4 \%$ \\
S04 & 12.73 & 12.42 & 0.32 & $2.5 \%$ \\
S03 & 11.15 & 11.18 & -0.03 & $0.2 \%$ \\
S02 & 7.28 & 7.35 & -0.07 & $0.9 \%$ \\
S01 & 7.75 & 4.74 & 3.01 & $38.8 \%$ \\
\hline
\end{tabular}

Tabela 8: Comparação dos resultados da modelagem com as cotas de cheia históricas..Fonte: Elaborada pela autora a partir de dados do DNOCS (2012).

Com a análise da tabela, percebe-se que os valores estão muito próximos dos observados em campo, onde a principal diferença se deu na seção 01. Tal diferença pode ser considerada aceitável, tendo em vista, primeiramente, que o objetivo da simulação em questão não foi obter as cotas de cheia históricas e sim simular os níveis d'água para determinados períodos de retorno de vazões afluentes ao Rio Piranhas-Açu, e, portanto, as vazões não coincidem com as ocorridas. Em segundo lugar, ainda pode haver incertezas em relação ao nível máximo medido em campo, haja vista que, em muitos casos, foram baseados em observações informais, sem medidas de precisão ou metodologias com embasamento científico. Em síntese, na comparação de todas as seções obteve-se um erro médio da ordem de $10 \%$, suficiente para assegurar a funcionalidade do modelo hidrodinâmico desenvolvido.

O gráfico 1 é resultante do perfil longitudinal do Rio Piranhas-Açu e os respectivos níveis d'água em relação à cota de fundo, da Ponte da BR-304 até a foz. 


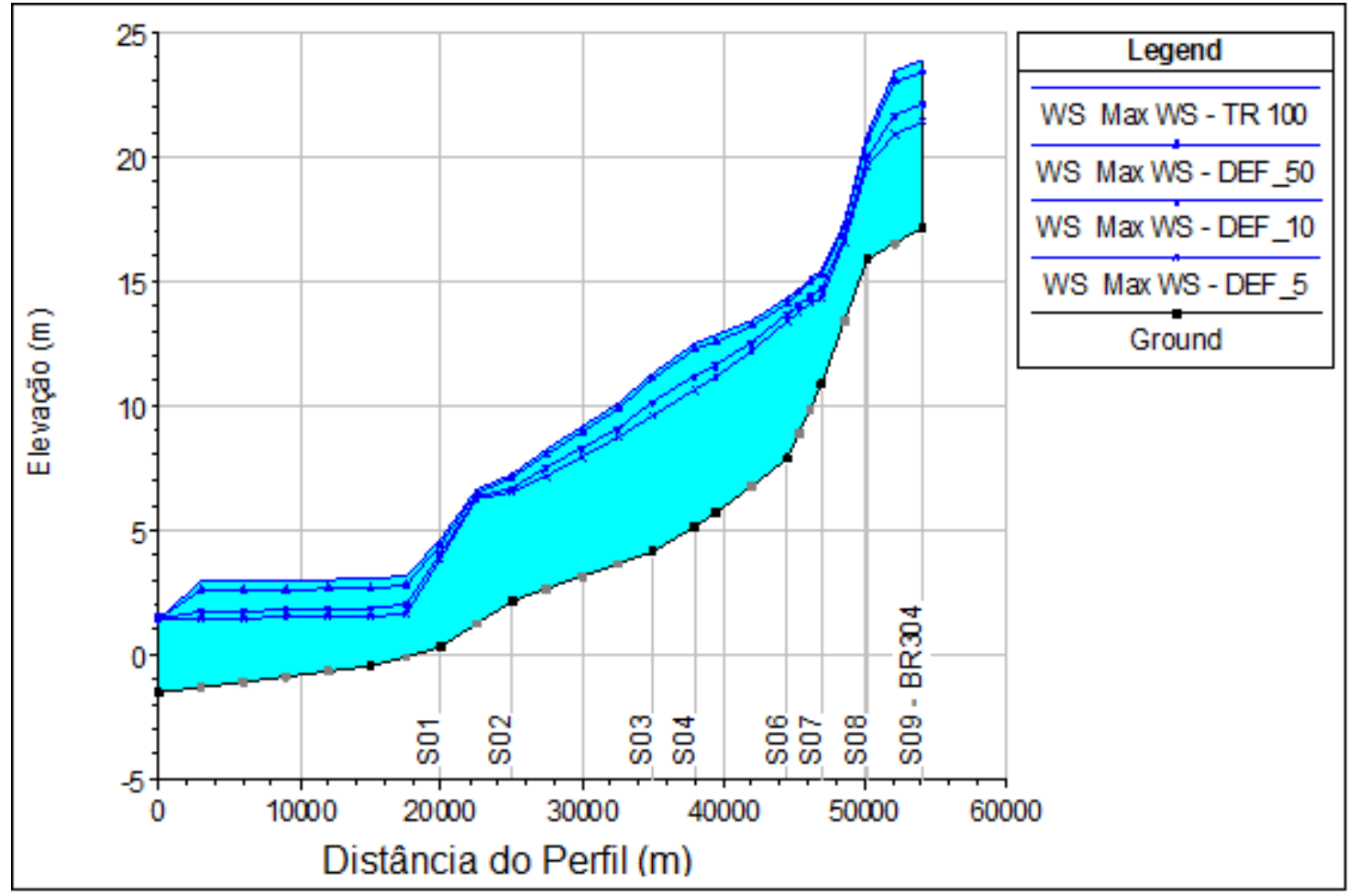

Gráfico 1: Perfil longitudinal dos níveis d'água. Fonte: Elaborada pelas autoras.

Os gráficos a seguir mostram os resultados obtidos na modelagem hidrológica para cada seção transversal da calha do Rio Piranhas-Açu. Assim, a seção transversal 09, gráfico 2, possui 81.095,79 metros de extensão e apresenta batimetria mínima de 17,13 metros. Para um período de retorno (ou tempo de recorrência) de 5 anos, a vazão total será de $2.035,59 \mathrm{~m}^{3} / \mathrm{s}$, atingindo o nível máximo de água numa cota de 21,36 metros, a velocidade da água será de $1,11 \mathrm{~m} / \mathrm{s}$ atingindo uma área equivalente a 1.839,12 $\mathrm{m}^{2}$. Para o período de recorrência de 10 anos a vazão será na ordem de 2.912,22 m³ $/ \mathrm{s}$, atingindo o nível máximo de água numa cota de 22,06 metros, a velocidade da água será de $1,3 \mathrm{~m} / \mathrm{s}$, abrangendo uma área de 2.240,43 $\mathrm{m}^{2}$. Para o período de recorrência de 50 anos a vazão será de $4.963,13 \mathrm{~m}^{3} / \mathrm{s}$, atingindo o nível máximo de água numa cota de 23,39 metros, a velocidade da água será de $1,65 \mathrm{~m} / \mathrm{s}$, abarcando uma área de $3.008,42 \mathrm{~m}^{2}$. Por fim, o período de recorrência de 100 anos mostrará uma vazão de $5.877,13 \mathrm{~m}^{3} / \mathrm{s}$, com nível máximo de água de 24,97 metros, a velocidade da água será de $1,49 \mathrm{~m} / \mathrm{s}$, compreendendo uma área de 3.938,08 m² O gráfico mostrado a seguir exibe cada uma das respectivas cotas atingidas por cada período de retorno calculado na modelagem hidrológica para a seção transversal 09. 


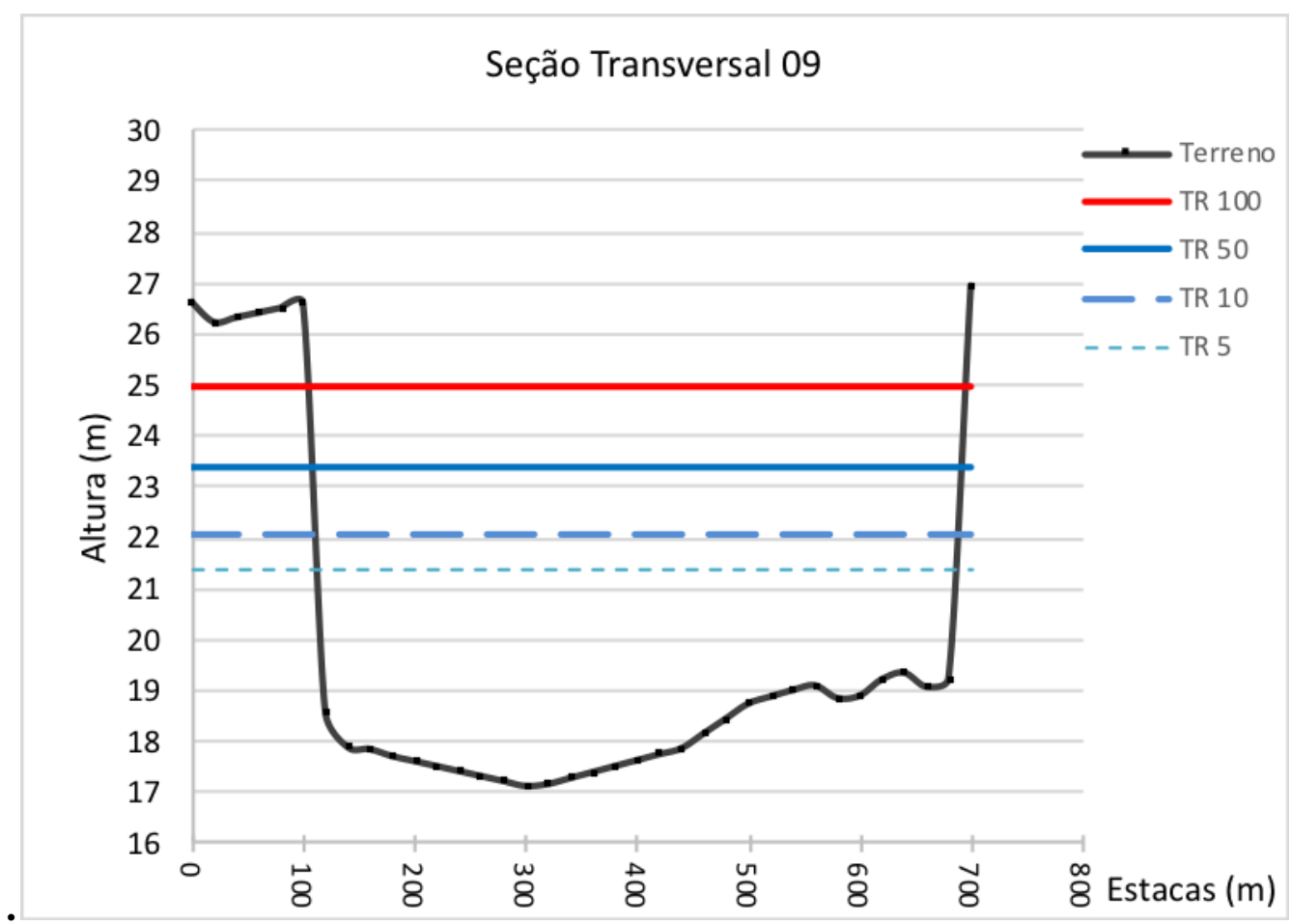

Gráfico 2: Cotas de inundação da Seção Transversal. Fonte: Elaborado pelas autoras.

A seção transversal 08 (gráfico 3) tem extensão de 77.036,04 metros e elevação mínima de 15,87 metros. Para o tempo de recorrência de 5 anos, a vazão total apresentada foi de $2.000,00 \mathrm{~m}^{3} / \mathrm{s}$, com nível máximo de água em 19,61 metros, a velocidade da água será de 1,34 m/s inundando uma área equivalente a 1.496,03 $\mathrm{m}^{2}$. Para o período de recorrência de 10 anos a vazão será na ordem de 2.910,61 m³ $/ \mathrm{s}$, atingindo o nível máximo de água numa cota de 19,94 metros, a velocidade da água será de $1,61 \mathrm{~m} / \mathrm{s}$, abrangendo uma área de 1.806,21 $\mathrm{m}^{2}$. Para o período de recorrência de 50 anos a vazão será de 4.962,57 m³/s, atingindo o nível máximo de água numa cota de 20,67 metros, a velocidade da água será de 1,79 m/s, abarcando uma área de 2.778,21 m². Já o período de recorrência de 100 anos mostrará uma vazão de $5.877,13 \mathrm{~m}^{3} / \mathrm{s}$ (semelhante à seção 09), com nível máximo de água de 21,59 metros, a velocidade da água será de 1,18 m/s, compreendendo uma área de 4.993,96 $\mathrm{m}^{2}$. O gráfico mostrado a seguir exibe cada as respectivas cotas atingidas por cada período de retorno calculado na modelagem hidrológica para a seção transversal 08. 


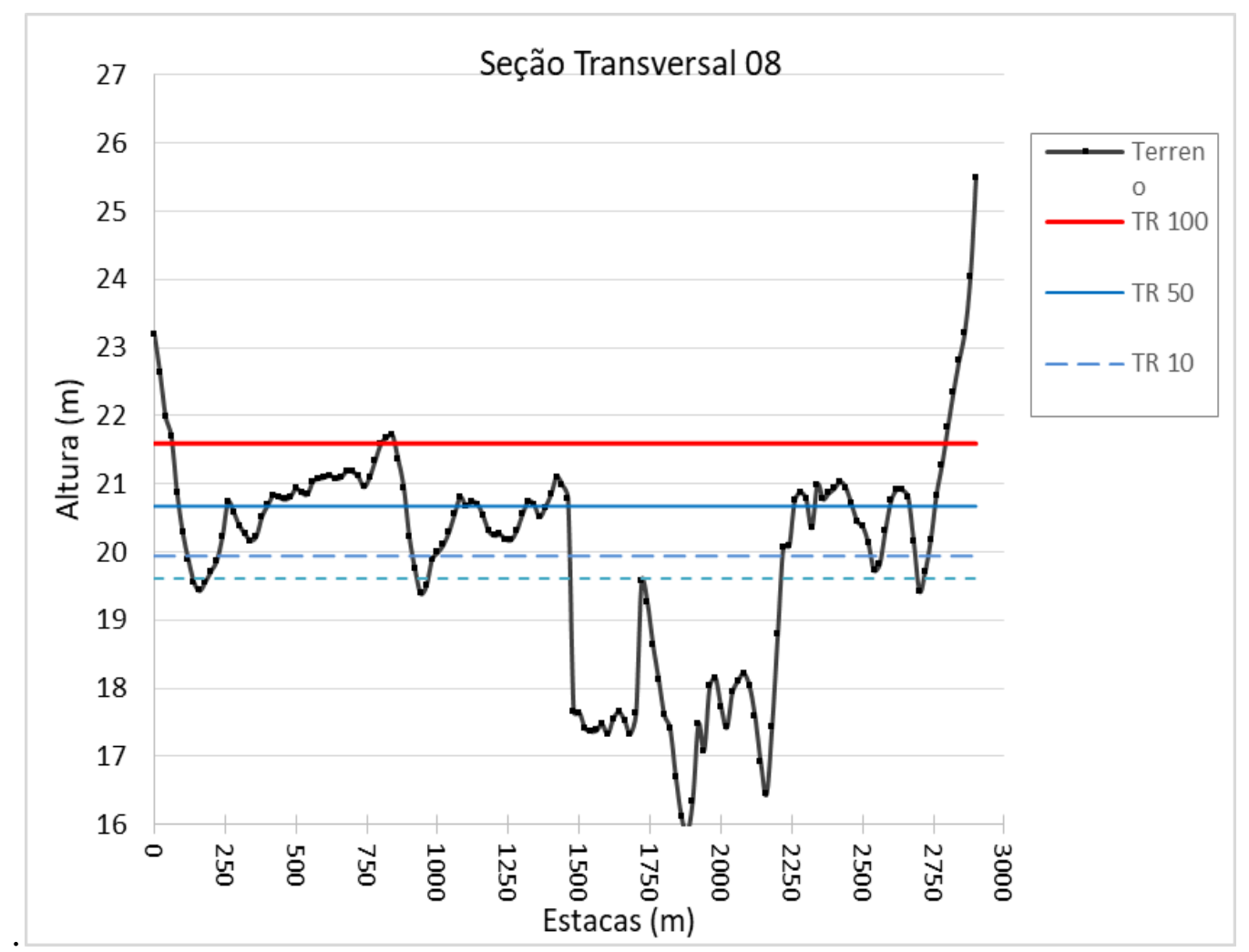

Gráfico 3: Cotas de inundação da Seção Transversal. Fonte: Elaborado pelas autoras.

A seção transversal 07 (gráfico 4) com extensão de 66.582,33metros e elevação mínima de sua calha igual a 10,88 metros, apresentou para tempo de recorrência de 5 anos, uma vazão total semelhante a seção 09, com nível máximo de água atingindo 14,32 metros, a velocidade da água foi calculada em 0,48 m/s submergindo uma área equivalente a 4.224,73 $\mathrm{m}^{2}$. Para o período de recorrência de 10 anos a vazão encontrada também é a mesma para seção 09, atingindo o nível máximo de água numa cota de 14,68 metros, a velocidade da água diminui para $0,52 \mathrm{~m} / \mathrm{s}$, compreendendo uma área de 5.558,35 $\mathrm{m}^{2}$. Para o período de recorrência de 50 anos a vazão será mais uma vez a mesma da seção 09, atingindo o nível máximo de água numa cota de 15,23 metros, a velocidade da água aumenta para 0,61 m/s, abarcando uma área de $8.072,14 \mathrm{~m}^{2}$. 0 período de recorrência de 100 anos mantém a mesma vazão das seções anteriores, com nível máximo de água de 15,39 metros de altitude, a velocidade da água será de $0,65 \mathrm{~m} / \mathrm{s}$, envolvendo uma área de $8.977,58 \mathrm{~m}^{2}$. 0 gráfico mostrado a seguir exibe cada uma as respectivas cotas atingidas por cada período de retorno calculado na modelagem hidrológica para a seção transversal 07. 


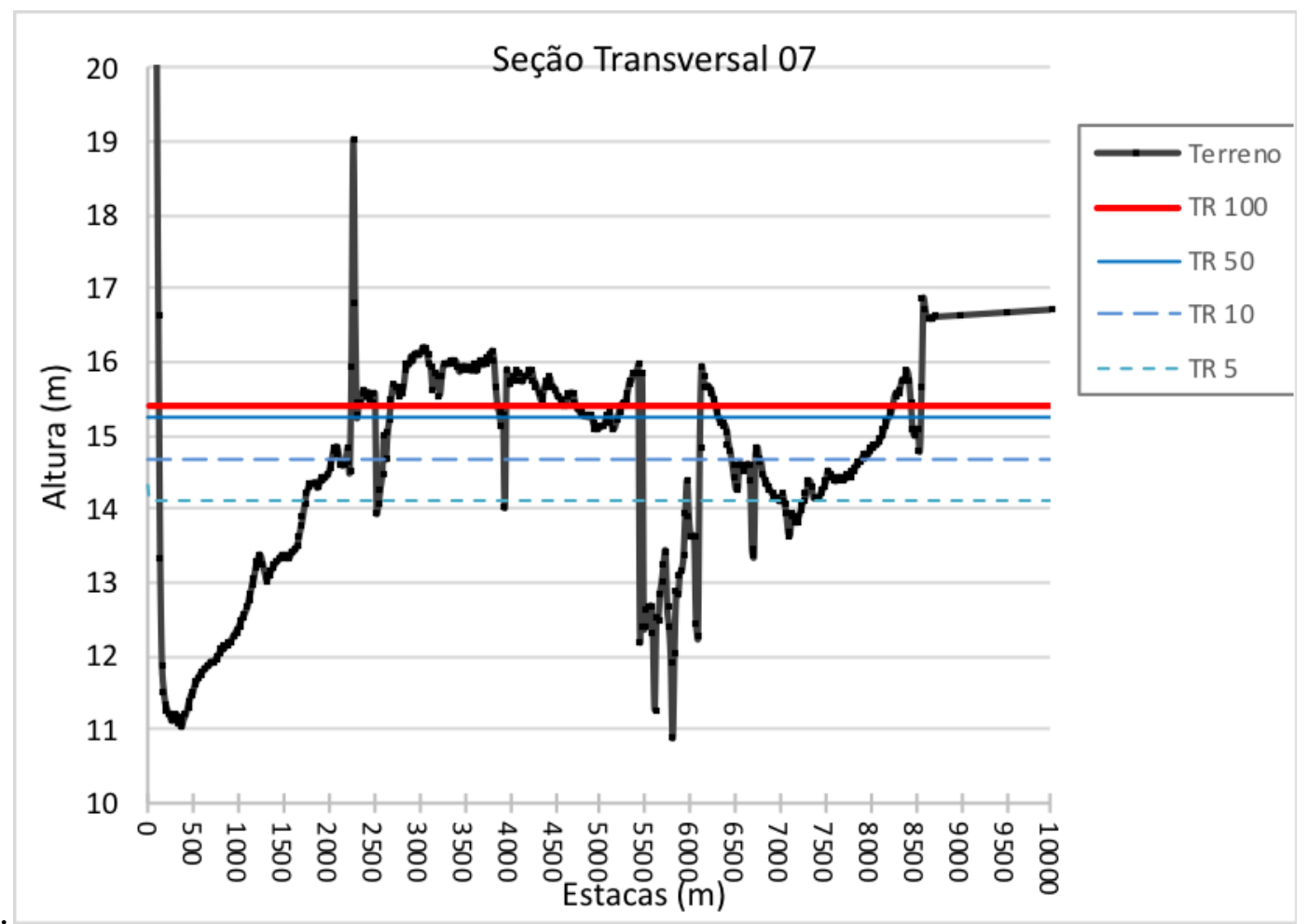

Gráfico 4: Cotas de inundação da Seção Transversal. Fonte: Elaborado pelas autoras.

A seção transversal 06 (gráfico 5), com extensão de 59.193,86 metros e elevação mínima de 7,85 metros, mostrou, segundo a modelagem, uma vazão total semelhante à seção 09, com nível máximo de água atingindo 13,37 metros, a velocidade da água aumentou para 0,62 m/s submergindo uma área equivalente a $3.264,82 \mathrm{~m}^{2}$, para o período de recorrência de 5 anos.

Para o período de recorrência de 10 anos a vazão encontrada será de $2.911,93 \mathrm{~m}^{3} / \mathrm{s}$, atingindo o nível máximo de água numa cota de 13,65 metros, a velocidade da água será de 0,69 m/s, imergindo uma área de 4.205,86 $\mathrm{m}^{2}$.

Para o período de recorrência de 50 anos a vazão será mais uma vez a mesma da seção 09, atingindo o nível máximo de água numa cota de 14,13 metros, a velocidade da água aumenta para 0,83 m/s, atravessando uma área de 5.950,88 $\mathrm{m}^{2}$. O período de recorrência de 100 anos também mantém a mesma vazão das seções anteriores, com nível máximo de água de 13,97 metros de altitude, a velocidade da água será de $1,09 \mathrm{~m} / \mathrm{s}$, invadindo uma área de $5.377,57 \mathrm{~m}^{2}$. 0 gráfico mostrado a seguir exibe cada uma as respectivas cotas atingidas por cada período de retorno calculado na modelagem hidrológica para a seção transversal 06. 


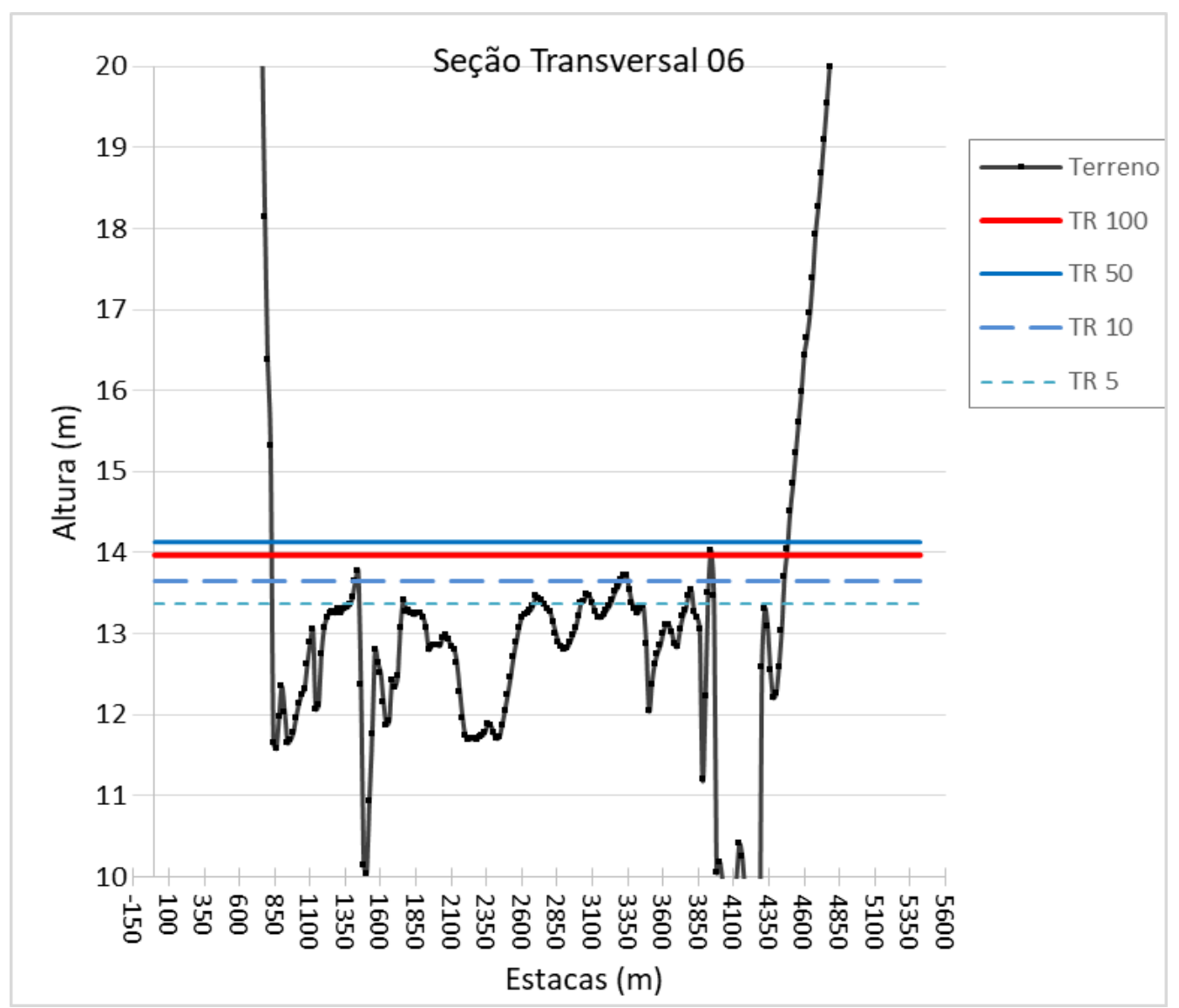

Gráfico 5: Cotas de inundação da Seção Transversal 06. Fonte: Elaborado pelas autoras.

A seção transversal 05 (gráfico 6) possui extensão de 54.233,91 metros e elevação mínima de 5,7 metros. Para o tempo de recorrência de 5 anos, a modelagem desta seção apresentou uma vazão total semelhante a seção 09, com nível máximo de água atingindo 11,12 metros, a velocidade da água foi calculada em 0,64 m/s submergindo uma área equivalente a $3.192,79 \mathrm{~m}^{2}$.

Para o período de recorrência de 10 anos a vazão encontrada também é a mesma para seção 09, atingindo o nível máximo de água numa cota de 11,62 metros, a velocidade da água se mantém e a área atingida é de $4.562,71 \mathrm{~m}^{2}$.

Para o período de recorrência de 50 anos a vazão será mais uma vez a mesma da seção 09, atingindo o nível máximo de água numa cota de 12,54 metros, a velocidade da água aumenta para 0,68 m/s, abarcando uma área de $7.324,59 \mathrm{~m}^{2}$. 
O período de recorrência de 100 anos mantém a mesma vazão das seções anteriores, com nível máximo de água de 12,97 metros de altitude, a velocidade da água continua a mesma do período de recorrência de 50 anos, envolvendo uma área de $8.614,85 \mathrm{~m}^{2}$. 0 gráfico mostrado a seguir exibe cada uma as respectivas cotas atingidas por cada período de retorno calculado na modelagem hidrológica para a seção transversal 05.

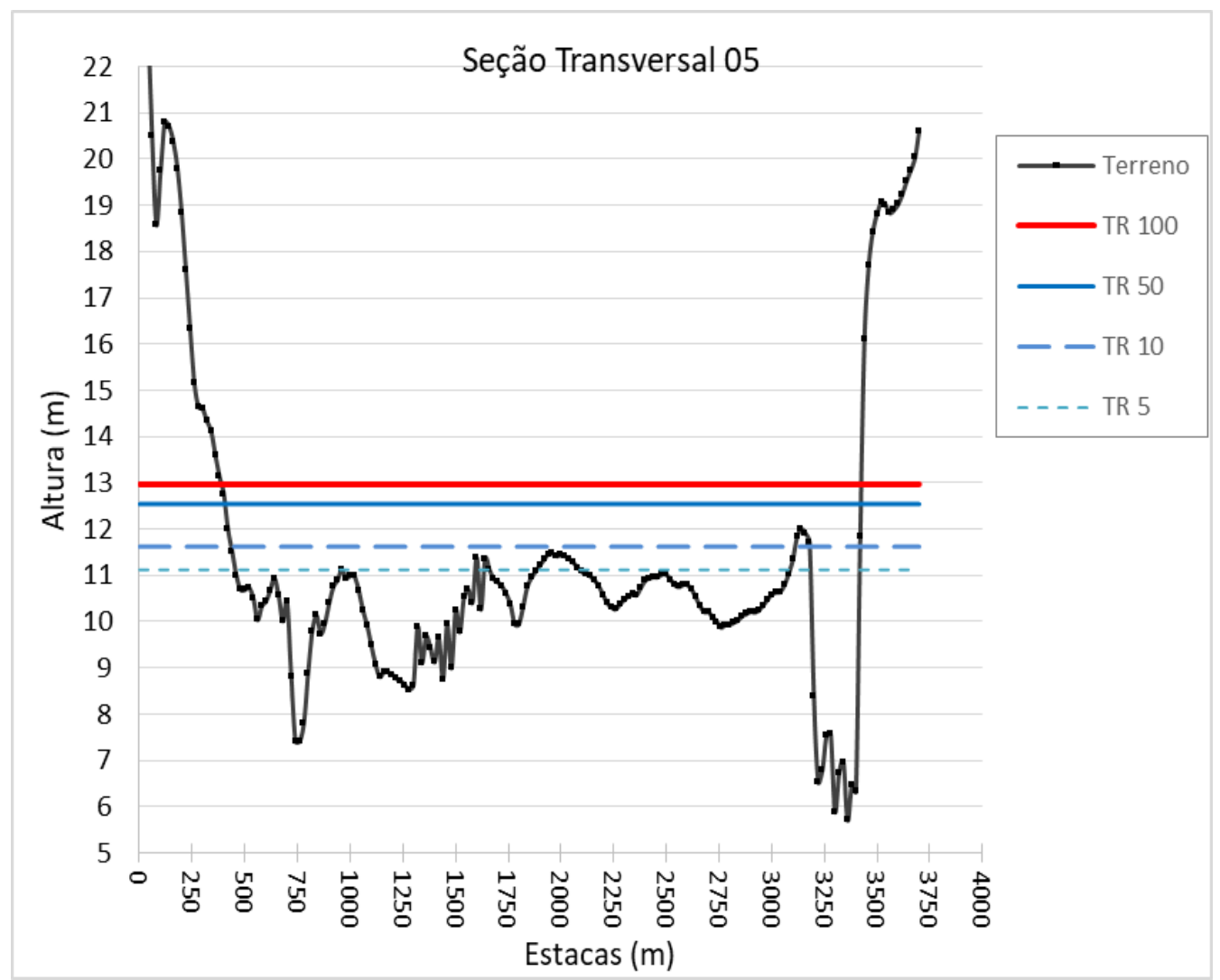

Gráfico6: Cotas de inundação da Seção Transversal 05.Fonte: Elaborado pelas autoras.

A seção transversal 04 (gráfico 7) tem uma extensão de 52.291,02 metros e elevação mínima de sua calha igual a 5,11 metros. Para o tempo de recorrência de 5 anos, a modelagem desta seção apresentou uma vazão total semelhante a seção 09, com nível máximo de água atingindo 10,62 metros, a velocidade da água foi calculada em $0,69 \mathrm{~m} / \mathrm{s}$ envolvendo uma área de inundação equivalente a $2.938,93 \mathrm{~m}^{2}$.

Para o período de recorrência de 10 anos a vazão encontrada também é a mesma para seção 09, atingindo o nível máximo de água numa cota de 11,22 metros, a velocidade da água aumenta para $0,71 \mathrm{~m} / \mathrm{s}$, compreendendo uma área de $4.073,63 \mathrm{~m}^{2}$. 
Para o período de recorrência de 50 anos a vazão será mais uma vez a mesma da seção 09, atingindo o nível máximo de água numa cota de 12,26 metros, a velocidade da água aumenta para 0,77 m/s, abarcando uma área de $6.471,20 \mathrm{~m}^{2}$.

O período de recorrência de 100 anos a vazão passa a ser igual a 5.877,12 $\mathrm{m}^{3} / \mathrm{s}$, com nível máximo de água de 12,57 metros de altitude, a velocidade da água será de 0,81 m/s, envolvendo uma área de $7.368,47 \mathrm{~m}^{2}$. O gráfico mostrado a seguir exibe cada uma as respectivas cotas atingidas por cada período de retorno calculado na modelagem hidrológica para a seção transversal 04.

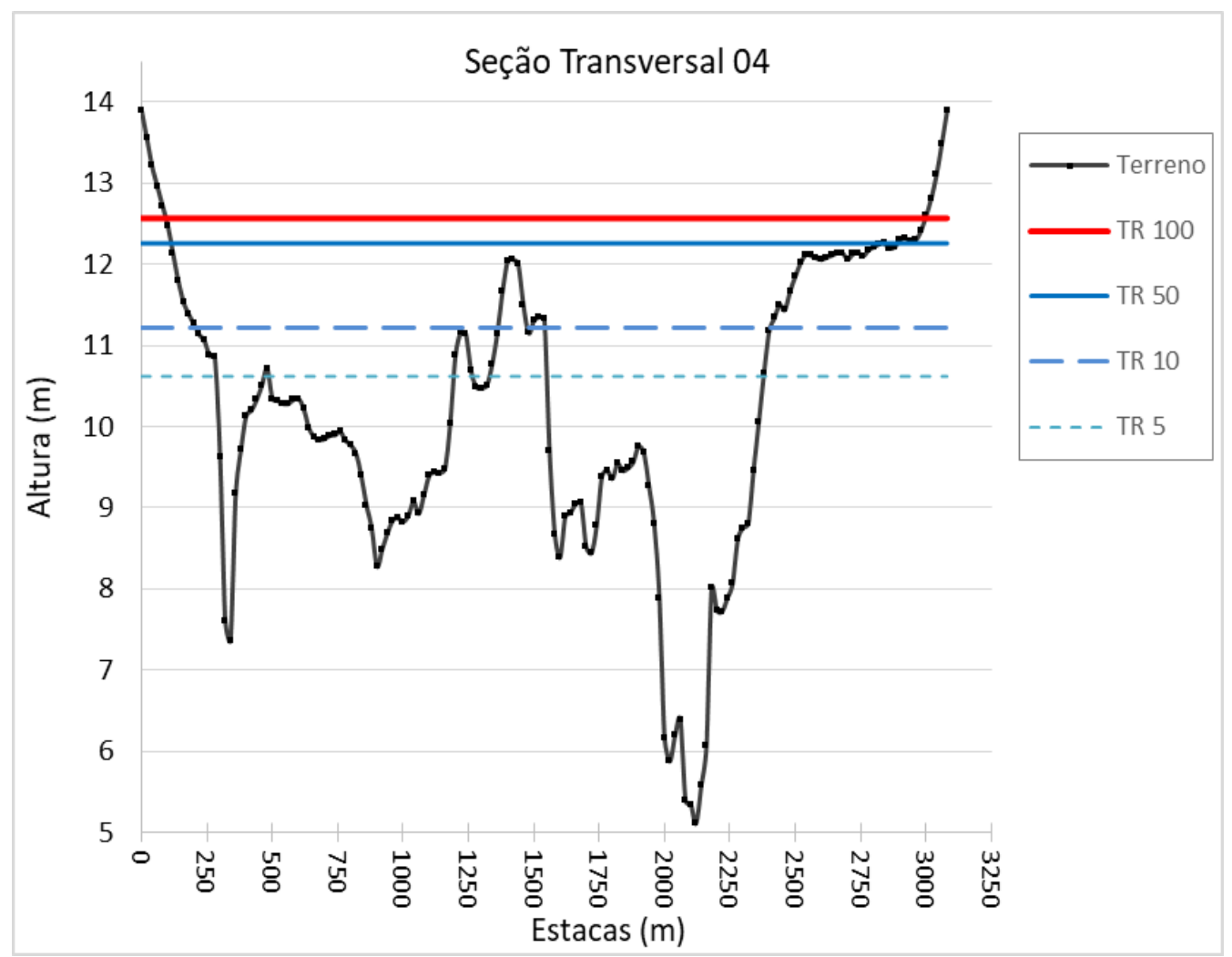

Gráfico 7: Cotas de inundação da Seção Transversal 04.Fonte: Elaborado pelas autoras.

A seção transversal 03 (gráfico 8) possui extensão de 50.521,06 metros e sua elevação mínima é igual a 4,15 metros. Para o tempo de recorrência de 5 anos, a modelagem desta seção apresentou uma vazão total semelhante a seção 09, com nível máximo de água atingindo 9,59 metros, a velocidade da água foi calculada em $0,92 \mathrm{~m} / \mathrm{s}$ submergindo uma área equivalente a $2.210,92 \mathrm{~m}^{2}$. 
Para o período de recorrência de 10 anos a vazão encontrada também é a mesma para seção 09, atingindo o nível máximo de água numa cota de 10,12 metros, a velocidade da água sobe para 1,04 $\mathrm{m} / \mathrm{s}$, compreendendo uma área de $2.787,15 \mathrm{~m}^{2}$.

Para o período de recorrência de 50 anos a vazão será mais uma vez a mesma da seção 09, atingindo o nível máximo de água numa cota de 11,06 metros, a velocidade da água aumenta para 1,1 m/s, abarcando uma área de 4.493,94 m². O período de recorrência de 100 anos mantém a mesma vazão da seção 09 com nível máximo de água de 11,29 metros de altitude, a velocidade da água será de 1,17 $\mathrm{m} / \mathrm{s}$, envolvendo uma área de $5.021,07 \mathrm{~m}^{2}$. 0 gráfico mostrado a seguir exibe cada uma as respectivas cotas atingidas por cada período de retorno calculado na modelagem hidrológica para a seção transversal 03.

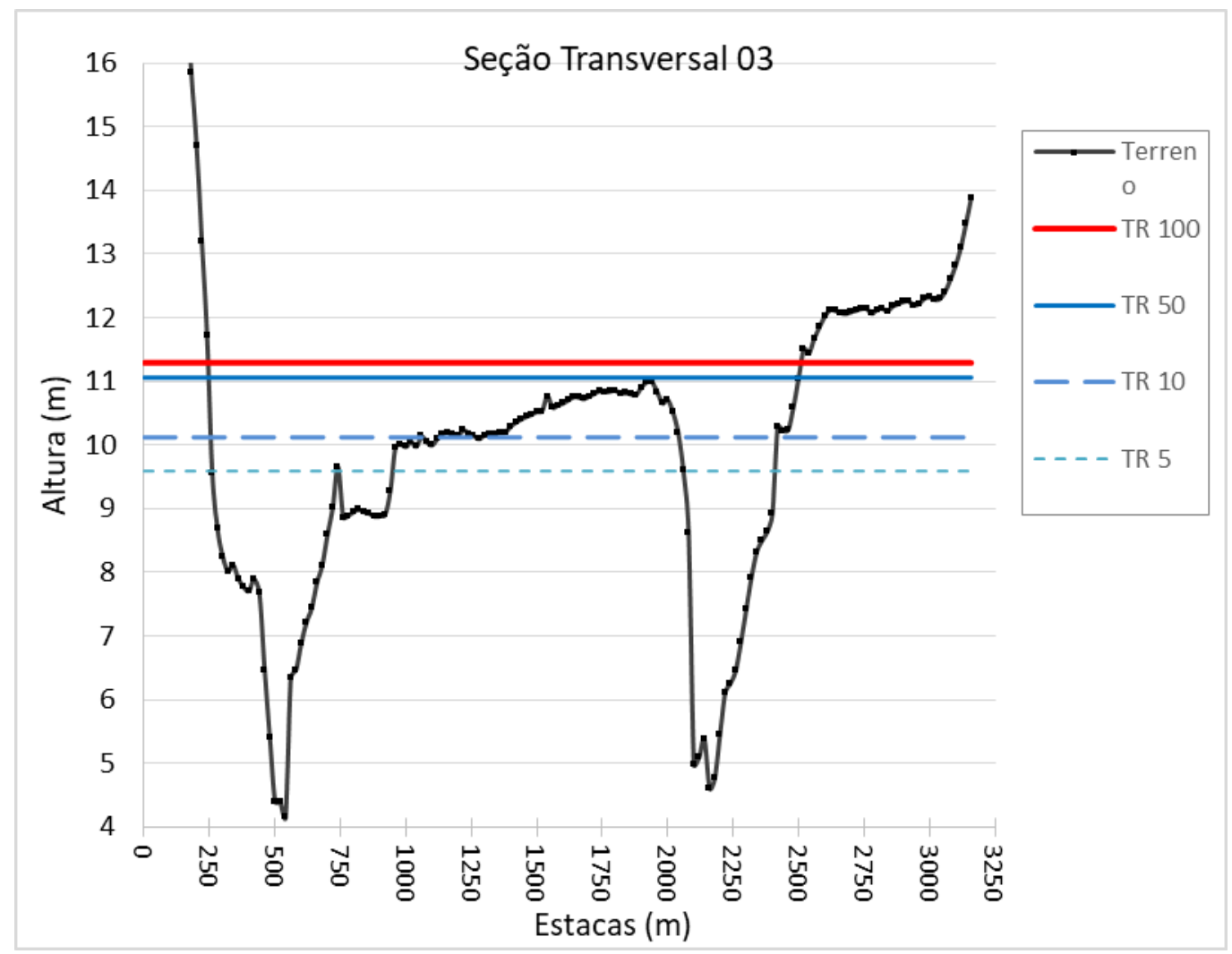

Gráfico 8: Cotas de inundação da Seção Transversal 03.Fonte: Elaborado pelas autoras.

A seção transversal 02 (gráfico 9) tem extensão de 38.687,64 metros e elevação mínima de 2,11 metros. Para o tempo de recorrência de 5 anos, a modelagem desta seção apresentou uma vazão total 
semelhante a seção 08, com nível máximo de água atingindo 6,52 metros, a velocidade da água foi calculada em 0,45 m/s, submergindo uma área equivalente a 4.486,34 m².

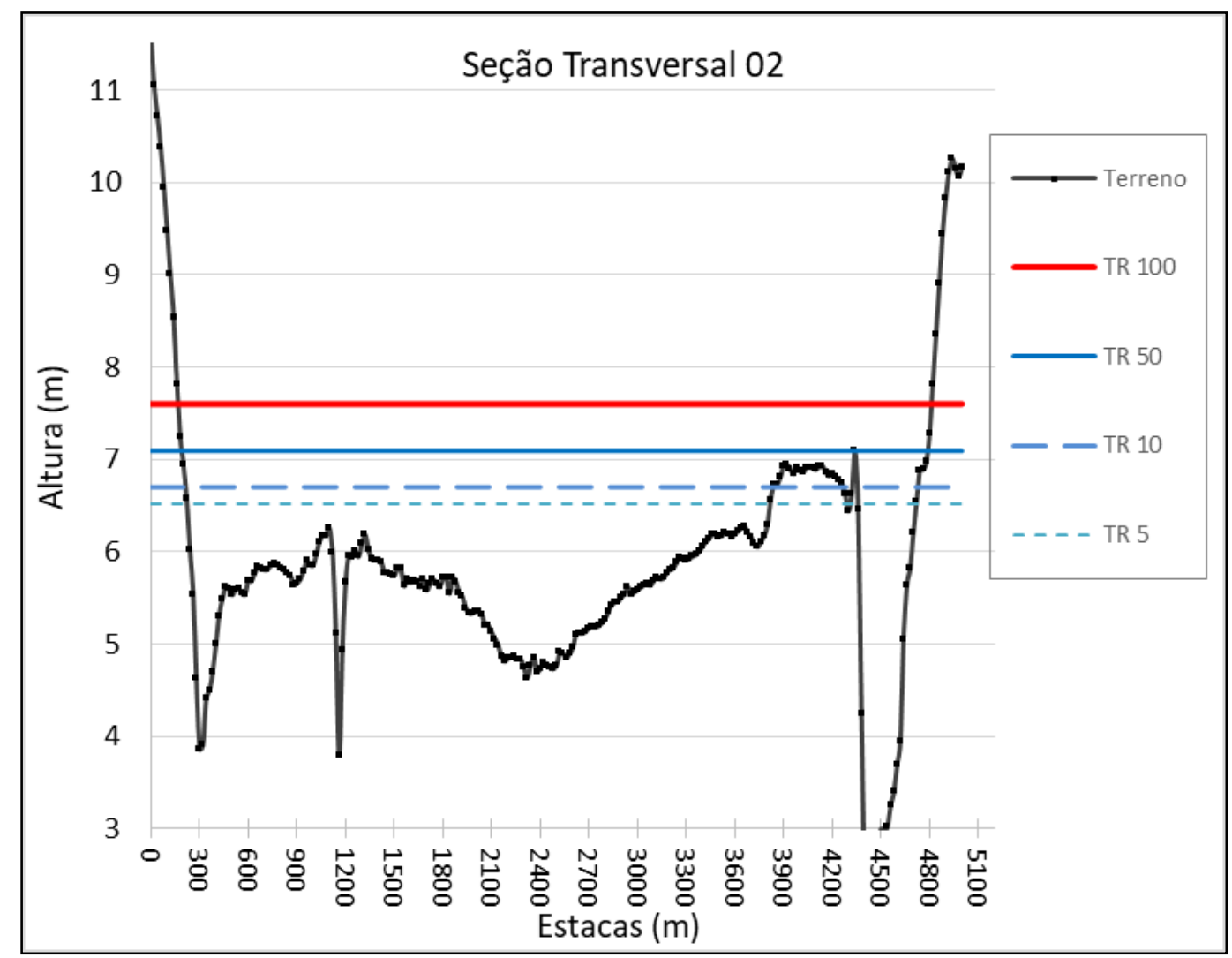

Gráfico 9: Cotas de inundação da Seção Transversal 02.Fonte: Elaborado pelas autoras.

Para o período de recorrência de 10 anos a vazão encontrada foi de $2.891,94 \mathrm{~m}^{3} / \mathrm{s}$, atingindo o nível máximo de água numa cota de 6,7 metros, a velocidade da água passa a ser igual a 0,56 m/s, compreendendo uma área de $5.207,52 \mathrm{~m}^{2}$.

Para o período de recorrência de 50 anos a vazão aumenta para $4.951,95 \mathrm{~m}^{3} / \mathrm{s}$, atingindo o nível máximo de água numa cota de 7,09 metros, a velocidade da água aumenta para $0,72 \mathrm{~m} / \mathrm{s}$, abarcando uma área de $6.888,88 \mathrm{~m}^{2}$.

O período de recorrência de 100 anos mantém a vazão passar a ser de $5.874,08 \mathrm{~m}^{3} / \mathrm{s}$, com nível máximo de água de 7,6 metros de altitude, a velocidade da água será de $0,63 \mathrm{~m} / \mathrm{s}$, envolvendo uma área de $9.267,91 \mathrm{~m}^{2}$. O gráfico mostrado a seguir exibe cada uma as respectivas cotas atingidas por cada período de retorno calculado na modelagem hidrológica para a seção transversal 02. 
A seção transversal 01(gráfico 10) conta com extensão de 32.174,83 metros (a menor seção), com elevação mínima igual a 0,32 metros. Para o tempo de recorrência de 5 anos, a modelagem desta seção apresentou uma vazão total semelhante $2.105,33 \mathrm{~m}^{3} / \mathrm{s}$, com nível máximo de água atingindo 3,86 metros, e velocidade da água calculada em $0,88 \mathrm{~m} / \mathrm{s}$, submergindo uma área equivalente a 2.402,67 $m^{2}$.

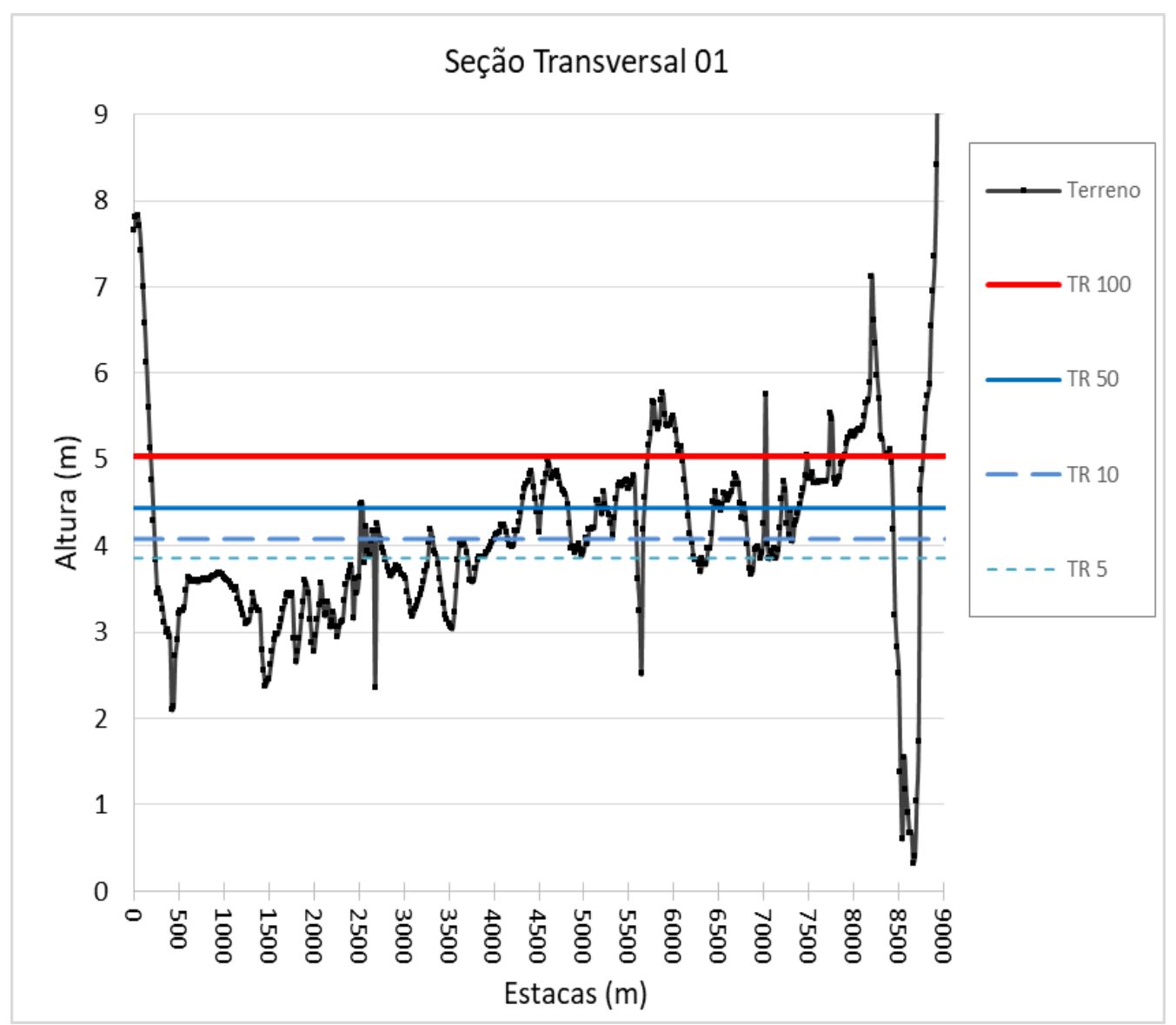

Gráfico 10: Cotas de inundação da Seção Transversal 01.fevereiro de 2016.). Fonte: Elaborada pela autora.

Para o período de recorrência de 10 anos a vazão encontrada foi igual a $2.999,32 \mathrm{~m}^{3} / \mathrm{s}$, atingindo o nível máximo de água numa cota de 4,08 metros, a velocidade da água passa a ser igual a 0,89 m/s, compreendendo uma área de $3.366,93 \mathrm{~m}^{2}$. 
Para o período de recorrência de 50 anos a vazão aumenta para $5.105,22 \mathrm{~m}^{3} / \mathrm{s}$, atingindo o nível máximo de água numa cota de 4,44 metros, a velocidade da água aumenta para $0,96 \mathrm{~m} / \mathrm{s}$, abarcando uma área de $5.302,04 \mathrm{~m}^{2}$.

O período de recorrência de 100 anos a vazão aumenta consideravelmente para $6.108,73 \mathrm{~m}^{3} / \mathrm{s}$, com nível máximo de água de 5,04 metros de altitude, a velocidade da água diminui para $0,65 \mathrm{~m} / \mathrm{s}$, envolvendo uma área de 9.350,91 $\mathrm{m}^{2}$ (a maior). O gráfico mostrado a seguir exibe cada uma as respectivas cotas atingidas por cada período de retorno calculado na modelagem hidrológica para a seção transversal 01.

Nesses casos é possível observar o forte efeito das cheias desse rio, cuja extensão transversal das inundações ultrapassa a ordem dos milhares de metros na maioria das seções levantadas.

Assim, a modelagem hidráulica realizada no contexto deste estudo permite observar a alta relevância dos efeitos de inundação promovidos pelas cheias do rio Piranhas-Açu no trecho do Baixo-Açu, demonstrando a necessidade de intervir através da construção de obras de controle destas cheias, a fim de se evitar as situações caóticas já vivenciadas no passado, com significativas perdas materiais, vidas humanas e rebanho.

\section{CONSIDERAÇÕES FINAIS}

A modelagem mostrou deficiência no tocante à precisão das cotas de inundação principalmente para a seção 01, tendo em vista a forte influência das marés nas áreas contempladas por esta seção. Assim, seria necessário um estudo das vazões específicas para esta área de forte interação fluviomarinha.

Até a seção 02, na altura do município de Pendências, a modelagem se mostrou satisfatória, quando comparados os dados obtidos na modelagem com os relados históricos dos moradores em campo.

Devido à falta de dados altimétricos de entrada mais precisos da calha do rio, não foi possível detalhar a batimetria, fazendo com que a acurácia de modelagem não seja maior. 
No caso do Rio Piranhas-Açu, as modelagens hidráulicas mostram que, até mesmo as cheias resultantes de vazões para períodos de retorno de baixo tempo de recorrência ( 5 e 10 anos), inundam grandes parcelas de áreas ao longo de toda a extensão da sua bacia.

Tal fato expõe a grande vulnerabilidade das regiões inseridas à jusante da Barragem Armando Ribeiro Gonçalves, que atualmente se encontram em risco permanente de inundações, sugerindo, assim, a necessidade urgente de utilização de medidas mitigadoras e de controle de enchentes nesse local.

\section{REFERÊNCIAS}

Agência Nacional de Águas (Brasil). Plano de recursos hídricos da bacia hidrográfica do rio Piranhas-Açu / Agência Nacional de Águas. - Brasília: ANA, 2010. 312 p.

ARAÚJO, P.V.N; AMARO, V.E.; ALCOFORADO, A.V.C.; SANTOS, A.L.S. Acurácia Vertical e Calibração de Modelos Digitais de Elevação (MDEs) para a Bacia Hidrográfica Piranhas-Açú, Rio Grande do Norte, Brasil. Anuário do Instituto de Geociências - UFRJ, v.41(1), 2018.

CHOW, V. T. Open-channel Hydraulies. New York: McGraw-Hill, 1959.

Departamento Nacional de Obras Contra as Secas (DNOCS). Estudos para proteção e controle de cheias na Bacia Hidrográfica do Rio-Piranhas-Açu nos estados do Rio Grande do Norte e Paraíba: Diagnóstico. Natal: DNOCS, 2012.3 .2 V.

Departamento Nacional de Obras Contra as Secas (DNOCS). Modelagem hidráulico/hidrológico da Bacia do Rio-PiranhasAçu: Modelagem hidrológica / hidráulica do Sistema Rio-Piranhas-Açu, com soluções para o controle de cheias na bacia. Natal: DNOCS, 2012. $1 \mathrm{v}$.

KOBIYAMA, M.; et al.Prevenção de desastres naturais-Conceitos básicos; Ed. Organic Trading, 1ํo Edição, Curitiba, PR, pp109, 2006.

IPCC: Managing the Risks of Extreme Events and Disasters to Advance Climate Change Adaptation. A Special Report of Working Groups I and II of the Intergovernmental Panel on Climate Change [Field, C.B., V. Barros, T.F. Stocker, D. Qin, D.J. Dokken, K.L. Ebi, M.D. Mastrandrea, K.J. Mach, G.-K. Plattner, S.K. Allen, M. Tignor, and P.M. Midgley (eds.)]. Cambridge University Press, Cambridge, UK, and New York, NY, USA, 2012, 582 pp.

PINTO, N. L. S.; HOLTZ, A. C. T.; MARTINS, J. A.; GOMIDE, F. L. S. Hidrologia Básica. São Paulo: Ed. Edgard Blucher, 1976.

OLIVEIRA, F. A. de et al. Uso de modelo hidrodinâmico para determinação da vazão a partir de medições de nível. Revista Brasileira de Recursos Hídricos, Porto Alegre,, v. 21, n. 4, p.707-718, dez. 2016.

PORTO, R. M. Hidráulica Básica. EESC-USP São Carlos SP - Progeto Reenge, 519p, 1999.

TUCCI, C e M (Ed.). OS DILEMAS DA SUSTENTABILIDADE DO SEMIÁRIDO. 2011. Disponível em: $<$ http://rhama.net/wordpress/?p=241>. Acesso em: 24 out. 2011. 